\title{
Non-Spatial and Spatial Models in Bioeconomics
}

by

\author{
Jon M. Conrad and Martin D. Smith ${ }^{\dagger}$
}

\begin{abstract}
Beginning in the 1960s, ecologists, mathematicians, and economists started developing a class of models which today are referred to as bioeconomic models. These early models started with a difference or differential equation describing the dynamics of a biological resource. To this equation one might add a second difference or differential equation describing the dynamics of "harvesting effort." Alternatively, one could formulate a dynamic optimization problem seeking to maximize discounted net benefit. These models provided important insights into the tragedy of the commons and policies that might promote optimal management. By the 1970s more complex models were developed incorporating multi-species interactions, age-structured populations, and models with stochastic growth. In the late 1990's, spatial bioeconomic models were developed in recognition of the importance of location when managing biological resources. The objectives of this survey are to (1) review some of the early models in bioeconomics, (2) present some of the key spatial models in bioeconomics that have been used to assess the value of marine (no-take) reserves, and (3) speculate on the direction of future research in spatial bioeconomics.
\end{abstract}

\section{Introduction and Overview}

Economics can be defined as the study of how society allocates scarce resources. Resource economics might then be defined as the study of how society allocates scarce natural resources. Academic studies on the economic importance of natural resources can be traced back to at least the late $19^{\text {th }}$ century and William Stanley Jevons' (W. S. Jevons, 1865) concern about the future of England in the face of a possible shortage of coal and arguably earlier to classical economists such as Thomas Malthus and David Ricardo. Coal, oil, and natural gas are examples of what economists would refer to as nonrenewable resources and there is an extensive economic literature now spanning more that 100 years. Renewable resources include both biological resources (naturally occurring plants and animals) and non-biological resources (for example, water, wind, and solar energy). In this survey we will focus on the role of economics in society's allocation of valuable biological resources. This focus reflects our interests, but it is also appropriate for this first issue of the $25^{\text {th }}$ anniversary volume of Natural Resource Modeling. Colin Clark, one of the co-founders of the Resource Modeling Association (RMA), is also one of

\footnotetext{
${ }^{\dagger}$ Jon Conrad is professor in the Dyson School of Applied Economics and Management at Cornell University and Martin Smith is The Dan and Bunny Gabel Associate Professor of Environmental Economics in the Nicholas School of the Environment and the Department of Economics at Duke University. Conrad gratefully acknowledges the support of the NSF through award 0832782. Smith thanks the Norwegian Research Council for financial support of this research.
} 
most important and influential scholars in the modeling and management of biological resources. In 1976, Wiley-Interscience published the first edition of Mathematical Bioeconomics: The Optimal Management of Renewable Resources. The third edition of this classic text was published in 2010. Bioeconomics is now a subfield spanning ecology, economics, and applied math and is concerned with models that integrate both population dynamics and economic value. The sheer volume of the literature in the field of bioeconomics is another reason to restrict our focus.

The early literature in bioeconomics was concerned with the open access harvest of commonpool fishery resources as well as their optimal management. While it may be difficult to imagine, as late as 1945 many believed marine fishery resources to be effectively unlimited in absolute terms and only limited in availability due to cost constraints (Smith and Wilen 2002). With the growth of industrial fishing in the post World War II era, this belief quickly gave way to an understanding that fish stocks could indeed be overfished, triggering the need for scientists and managers to understand this phenomenon. Early bioeconomic models began to emerge in this context as a means to understand the role of rent- or profit-seeking in the over-exploitation of a common-pool renewable resource. The economic history of whaling, sealing, and fishing provided motivation for early bioeconomic work with many examples of resource depletion and occasionally extinction.

A natural starting place for bioeconomics was to study the problem of open access, when there are no restrictions on the harvest of a common-pool resource. Like private goods, open access goods are rival in consumption; one agent's capture of a fish makes that fish unavailable to other agents. But unlike private goods for which property rights exclude users, open access goods are plagued by non-excludability. The ability for anyone to harvest a fish under open access is the principal source of market failure. Models of this institutional arrangement are now referred to as "pure open access" to distinguish them from models of arrangements in which some regulations exist but access to the resource is still open. Interestingly, Colin Clark refers to the model of pure open access as the "bionomic model."

The static version of pure open access was described by H. Scott Gordon (1954), a full 14 years before the publication of Garrett Hardin's "Tragedy of the Commons," which appeared in Science in 1968. Gordon's model succinctly showed that open access would lead to biological overexploitation, excess fishing effort, and ultimately the dissipation of economic rents. The paper contained both positive content - a description of the effects of open access on fish stocks and fishing effort - and normative content - a claim about what would be optimal.

Just one year after Gordon's paper on open access, Anthony Scott (1955) pondered a dynamic extension of Gordon's analysis. If the problem of overexploitation in the commons could be solved by having a sole owner rather than open access (solving the non-excludabilty problem), 
then the sole owner would consider how harvesting in one period affects the availability of stock in future periods and adjust behavior accordingly. This contribution, while seemingly tautological by modern standards, laid the foundation for later work in the 1960s and early 1970s that cast optimal management of renewable resources in a dynamic framework using optimal control theory. With Scott's insights, economists needed to think about stocks and harvest over time, necessitating an integration of fishing behavior and fish population dynamics. Thus, bioeconomic modeling required economists to study the theory of nonlinear dynamical systems. Responding to this need, in 1969 Vernon Smith (1969) developed a dynamic version of the pure open access model using differential equations with myopic, rent-seeking behavior.

Smith's model would seem an appropriate paradigm for modeling whaling, sealing and fishing in the $18^{\text {th }}$ and $19^{\text {th }}$ centuries, but it also contributed to another intellectual development. Mathematicians and scientists in related fields in the early 1970s were developing a richer understanding nonlinear dynamics and finding examples of complex behaviors emerging from fairly simple model structures, including models of population dynamics (May 1976). While bioeconomists continued to develop positive models to understand the problem of resource exploitation in general and normative models to inform optimal management, coupling population dynamics to economics spawned a purely intellectual interest in determining the types of dynamic behavior that bioeconomic models might exhibit. Our review touches on all three of these areas: bioeconomics as a means to understand the exploitation of biological resources and inform empirical studies, bioeconomics as a means to develop optimal management policies, and bioeconomics as an source of interesting nonlinear systems.

In the next section we will review the models describing pure open access, regulated open access, optimal management when growth is deterministic, and optimal escapement when growth is stochastic. Section three will extend these non-spatial models to allow for dispersal over a set of "patches" as well as incentives for harvesters to seek patches with the highest economic rent. These spatial models have been important in assessing the location and value of marine (no-take) reserves. The fourth section concludes with a discussion of the likely future frontiers in spatial bioeconomics.

\section{Bioeconomics: Early Models}

\section{Pure Open Access}

The world did not need economists to have a basic understanding of the long-term prospects of a common pool resource harvested by competitive, profit (rent)-seeking individuals. Early history notes the deforestation of the Mediterranean by an expanding Roman Empire [O'Sullivan et al. (2008)], overgrazing in England and Wales [Kain et al. (2004)], and overfishing in the coastal waters of medieval Europe [Barrett et al. (2004)]. But economic models are critical for identifying the source of market failure, informing empirical studies of these coupled systems, and making policy prescriptions for optimal management. Mathematical models describing the 
dynamics of both a fish population and the industry harvesting that population can be found in Crutchfield and Zellner (1962), Smith (1968, 1969) and Clark (1973). These early models built on Gordon (1954) and Scott (1955) and borrowed from the pioneering work of fisheries scientists Schaefer (1957) and Beverton and Holt (1957), who provided key insights on how to link population dynamics to harvests and ultimately harvester behavior, informing both theoretical and empirical model development in bioeconomics. Compared to many other biological resources such as forests, empirical models of fish have the added challenge that the fish cannot be directly observed and stock dynamics must be inferred indirectly. From these seminal studies there emerged a model now referred to as "the pure open-access model."

We will formulate the pure open access model in discrete time rather than the more conventional continuous-time. This presents some added complexity (though arguably added generality), in terms of possible dynamic behavior.In our review, it will allow us to use a consistent notation for the non-stochastic and stochastic models and to set the stage for the spatial models in Section III.Beyond expedience for a review article, discrete-time models may be preferable when one is developing a model where functional forms will be specified and the parameters of those functions calibrated or estimated using time-series data. Empirical studies of commercial fisheries can then provide a "reality check" on a class of models and sometimes identify functional forms that best describe harvest, growth, and the dynamics of a particular resource. Two empirical models of the pure open access case provide such reality checks: one using continuous time to analyze the fur seal harvest (Wilen 1976) and one using discrete time to model the herring fishery (Bjorndal and Conrad 1987). Both find evidence of the dynamics that we describe below.

Consider a fish population where the stock is measured in units of biomass (eg. metric tons) and is denoted by the variable $X_{t}$. Let harvest be denoted by $Y_{t}$ and assume a Schaefer production function, $Y_{t}=q X_{t} E_{t}$, where $q>0$ is the catchability coefficient (a constant) and $E_{t}$ is fishing effort. Suppose the net growth in the fish population is appropriately modeled by the logistic function and that the change in fish biomass, going from period $t$ to period $t+1$, is described by the first-order difference equation $X_{t+1}-X_{t}=r X_{t}\left(1-X_{t} / K\right)-q X_{t} E_{t}$, with $r>0$ being the intrinsic growth rate and $K>0$ the stock's environmental carrying capacity. If fishing effort were constant, so that $E_{t}=E \geq 0$, we could define $q E \equiv \gamma$. Presumably $r>\gamma \geq 0$, and the evolution of the fish stock could be simulated by the iterative map $X_{t+1}=\left[1+r-\gamma-r X_{t} / K\right] X_{t}$ from an initial condition, $X_{0}>0$. This map has a steady state at $X_{S S}=K(r-\gamma) / r$. A necessary and sufficient condition for $X_{S S}$ to be locally stable is $|1-r+\gamma|<1$, where $|\bullet|$ is the absolute value operator. Since $Y_{t}=\gamma X_{t}$ we might refer to this as a constant proportion harvest policy. 
To obtain a model of pure open access we need to pair the equation for fish stock dynamics with an equation for effort dynamics, which allows $E_{t}$ potentially to vary from period to period. A myopic model of effort dynamics might assume that effort would increase if profit (rent) were positive and would decrease if profit (rent) were negative. Let $p>0$ denote the per unit (constant) price for fish on the dock and $c>0$ the per unit cost of effort. Then profit or rent in period $t$ can be defined as $\pi_{t}=p q X_{t} E_{t}-c E_{t}$. The change in effort under pure open access is then modeled by the equation $E_{t+1}-E_{t}=\eta\left[p q X_{t} E_{t}-c E_{t}\right]$, where $\eta>0$ is an effort-adjustment or stiffness parameter, which captures the empirical reality of sluggish adjustment of the harvest sector when profits are positive or negative.

We can now write the pure open access system as

$$
\begin{aligned}
& X_{t+1}=\left[1+r-r X_{t} / K-q E_{t}\right] X_{t} \\
& E_{t+1}=\left[1+\eta\left(p q X_{t}-c\right)\right] E_{t}
\end{aligned}
$$

This system has a steady state, $\left[X_{\infty}, E_{\infty}\right]$, where $X_{\infty}=c /(p q)$ and $E_{\infty}=r(p q K-c) /\left(p q^{2} K\right)$. The model is essentially a discrete-time version of Smith $(1968,1969)$. We will assume that $p q K-c>0$ so that both $X_{\infty}$ and $E_{\infty}$ are positive. In steady state, rent, $\pi_{t}=p q X_{t} E_{t}-c E_{t}$, has been driven to zero as was described by Gordon (1954). However, in transition positive and negative rents are possible, and this result will extend to spatial models described in the next section.

Analysis of steady states in bioeconomic models is useful for several reasons. First, it is often possible to characterize steady states analytically, whereas transition dynamics in most models must resort to numerical simulation. With an analytical steady state, the analyst can perform comparative statics on parameters of the system, exploring how long-run economic and biological outcomes will change in response to changes in costs, prices, or biological productivity. Second, local behavior around steady states can be informative about the transition dynamics and provide predictions about qualitative behavior of the system, which in turn can be used in empirical studies. We will illustrate this analysis below using the Jacobian Matrix. Third, policies for managing biological resources often target steady-state outcomes. For instance, fishery management in many countries attempts to achieve Maximum Sustainable Yield (MSY), which typically is thought of as a steady-state result. By analyzing steady states, we can compare objectives like MSY to steady states that emerge from pure open access as well as from optimal management. Drawbacks of focusing on steady states stem from the fact that bioeconomic systems are rarely (if ever) in a steady state. As a result, the data that we see tends to reflect transition dynamics. When multiple steady states are possible and/or the dynamics are particularly nonlinear, the sharpness of model predictions from linearized steady states can break down. 
With these strengths and weaknesses in mind, the Jacobian Matrix for this pure open access system in (1), when evaluated at $\left[X_{\infty}, E_{\infty}\right]$, may be written as

$$
J=\left[\begin{array}{cc}
(p q K-r c) /(p q K) & -c / p \\
\eta r(p q K-c) /(q K) & 1
\end{array}\right]
$$

The absolute value of the trace of $J$ is given by $|\operatorname{Tr}(J)|=|(p q K-r c) /(p q K)+1|$ while the determinant of $J$ is $\operatorname{det}(J)=[(p q K-r c)+\eta c r(p q K-c)] /(p q K)$. It is well known [Edelstein-Keshet (1988, p.57)] that a necessary and sufficient condition for the stability of $\left[X_{\infty}, E_{\infty}\right]$ is $2>1+\operatorname{det}(J)>|\operatorname{Tr}(J)|$. This sufficient condition, for our two-equation system, is an example of the Jury Test, and can be generalized to dynamical systems of more that two difference equations. See Jury (1971). In discrete time, this pure open access system is capable of more complex dynamics than its continuous-time counterpart as analyzed in Clark (1990, pp. 189-190) ${ }^{1}$. In this discrete-time system, $\left[X_{\infty}, E_{\infty}\right]$ may be stable (a sink), the focus of a stable limit cycle, or unstable (a source), where initial conditions overshoot $\left[X_{\infty}, E_{\infty}\right]$ with the fish stock and effort going to extinction, $\left[X_{\infty}, E_{\infty}\right]=[0,0]$, which is stable. These three outcomes are shown in Figure 1. The possibility of a multiple qualitative regimes for transition dynamics poses empirical problems (Smith 2008). However, the world is what it is and one might argue that assuming continuous time that rules out the cases in Figures $1 \mathrm{~b}$ and $1 \mathrm{c}$ could be misleading in empirical work.

Figure 1. The Pure Open Access System when $c=1, K=1, p=200, q=0.01, r=0.1$, and (a) $\eta=0.3$, (b) $\eta=1$, and (c) $\eta=1.3$ when simulated from $\left[X_{0}, E_{0}\right]=[0.5,1]$. In (a)(c), $\left[X_{\infty}, E_{\infty}\right]=[0.5,5]$. In (a), $\left[X_{\infty}, E_{\infty}\right]$ is a sink (a stable spiral). In (b), $\left[X_{\infty}, E_{\infty}\right]$ is the focus of a stable limit cycle. In (c), $\left[X_{\infty}, E_{\infty}\right]$ is a source (the focus of an unstable spiral). All trajectories move counter-clockwise.

\footnotetext{
${ }^{1}$ Clark (1990) shows in the continuous-time analogue to System (1) that $\left[X_{\infty}, E_{\infty}\right]$ can only be a stable node or a stable spiral. Using the Bendixson-Du Lac Criterion he also rules out the possibility of limit cycles.
} 


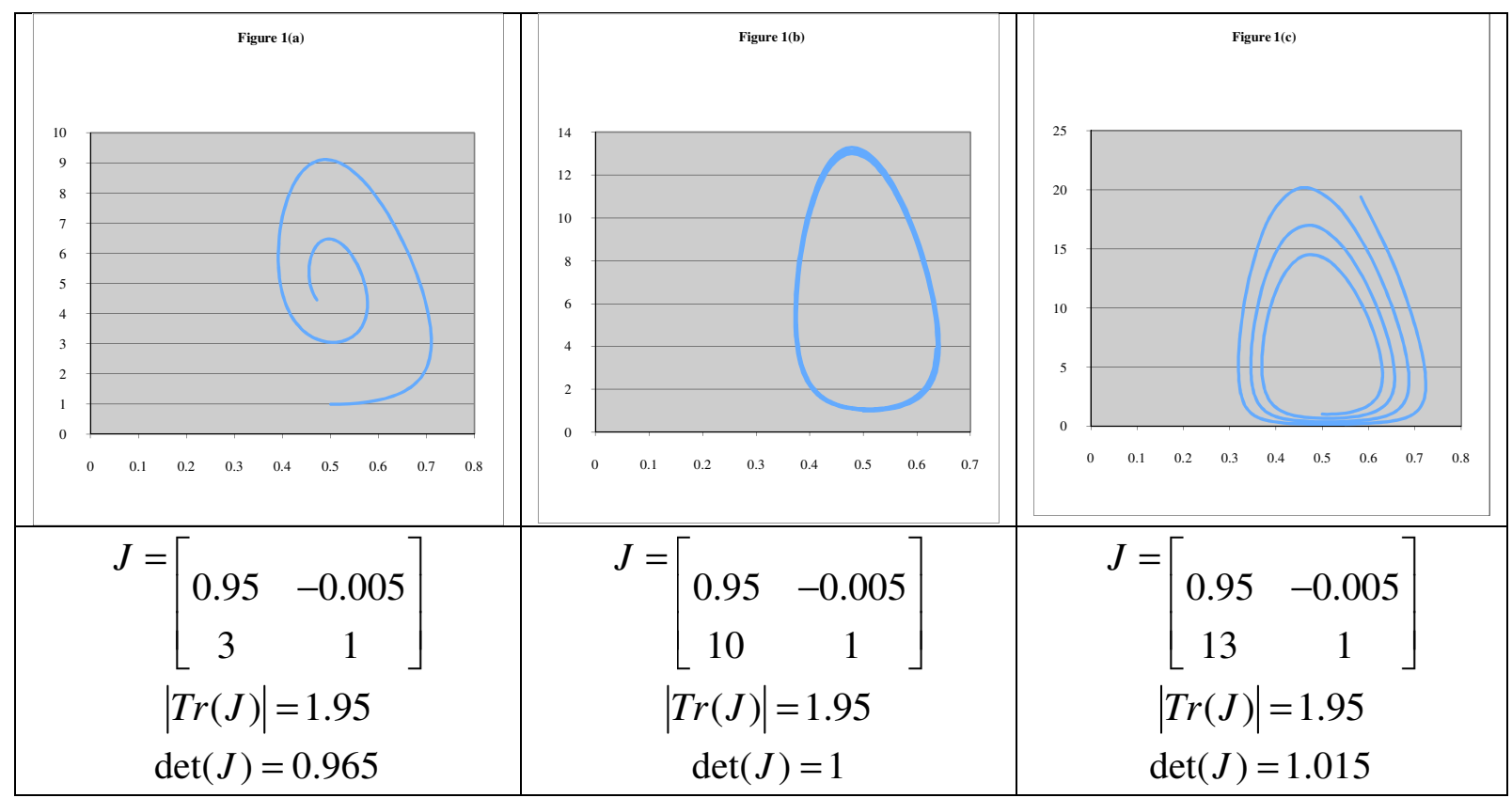

When $\eta=0.3$, Figure 1(a) shows the start of spiral convergence to $\left[X_{\infty}, E_{\infty}\right]=[0.5,5]$. Note that the stability condition, $2>1+\operatorname{det}(J)>|\operatorname{Tr}(J)|$, is satisfied. When $\eta$ increases to $\eta=1$ the determinant increases to $\operatorname{det}(J)=1$, the stability condition is not satisfied and $\left[X_{\infty}, E_{\infty}\right]=[0.5,5]$ is the focus of a stable limit cycle. Finally, when $\eta$ increases to $\eta=1.3$, the determinant increases to $\operatorname{det}(J)=1.015$, the stability condition is not satisfied and $\left[X_{\infty}, E_{\infty}\right]=[0.5,5]$ is the focus of an unstable spiral whose destination is extinction or $\left[X_{\infty}, E_{\infty}\right]=[0,0]$.

\section{Regulated Open Access}

As scientists developed a deeper understanding of bioeconomic systems in the 1950s, 1960s and 1970s, policy measures focused almost exclusively on the control of biological overfishing. Policies largely ignored the economic consequences with a presumption that controlling biological overfishing would fix the fishery problem. In essence, policies did not consider the root cause of the fishery problem as described by Gordon (1954), namely non-excludability. As a result, many governments responded to the overfishing that resulted from pure open access by simply imposing an upper bound on total allowable catch (or a TAC) (Homans and Wilen 1997). This extension was made possible in part by nations extending their exclusive economic zones in the 1970s, allowing regulators to enclose the fishing commons. However, the ways in which regulators began to enclose these commons were not bioeconomic. By limiting attention to the control of catch, managers framed their objective as avoiding bad biological consequences rather than promoting good economic and biological outcomes. To a large extent, we are stuck with this objective today as codified in the U.S. Magnuson-Stevens Fishery Conservation and 
Management Act, though language in the recent reauthorization of the act has started to acknowledge the economic component of bioeconomics.

Homans and Wilen (1997) developed a positive bioeconomic model of the fishery to understand the consequences of the biological regulation that many industrialized countries practice. Although catching too many fish is one consequence of open access, setting a TAC does not solve the underlying institutional failure. Regulation using a TAC requires the government to monitor catch as it accumulates during a season. When cumulative catch reaches the TAC the season is closed. While a TAC might prevent the low stock levels typically seen under pure open access, they often result in "a race for the fish" and a compressed fishing season, with large harvests being landed during sometimes only a few days of intensive fishing. Fish that cannot be sold fresh must be frozen, often resulting in a lower dockside price paid to fishermen. In their race to catch as large a share of the TAC for themselves, fishermen may overload their vessels or take other unadvisable risks that could cause a fishing vessel to capsize. This was an accurate description of what happened in the Alaskan halibut fishery from the 1960s to the early 1990s when the season went from lasting almost six months to lasting only a few days and where the short season was referred to as the "halibut derby."

In addition to stock size and fishing effort, the model of regulated open access endogenously determines season length, denoted $T_{t}$. In essence, the fish stock, the behavior of the fleet, and the behavior of the regulator are all modeled jointly. Cumulative harvest is determined by a production function where $Y_{t}=X_{t}\left(1-e^{-q E_{t} T_{t}}\right)$. With a logistic net growth function the change in the fish stock from year $t$ to year $t+1$ is given by the first-order difference equation $X_{t+1}-X_{t}=r X_{t}\left(1-X_{t} / K\right)-X_{t}\left(1-e^{-q E_{t} T_{t}}\right)$. Homans and Wilen identified both variable and fixed costs in the Alaskan halibut fishery and defined net revenue or rent in year $t$ as $\pi_{t}=p X_{t}\left(1-e^{-q E_{t} T_{t}}\right)-v E_{t} T_{t}-f E_{t}$, where $p>0$ is the per unit, dockside, price, $v>0$ is a variable cost coefficient, and $f>0$ is a fixed cost coefficient.

Homans and Wilen assumed that management authorities set the TAC in year $t$ according to a linear TAC policy where $T A C_{t}=c+d X_{t}$ and that actual harvest in each year equals the TAC. One would normally expect $c \leq 0$, and $d>0$ so that the TAC policy would be a constant proportion policy $(c=0)$ or a piece-wise linear policy exhibiting a minimum population level ( $c<0$ ) before a positive harvest is allowed. As we will see, this was not the case when the TAC policy was estimated for the Pacific halibut in Areas 2 and 3 as regulated by the International Pacific Halibut Commission. The actual rule estimated empirically by Homans and Wilen implies a positive TAC when the stock is zero. As a practical matter, the TAC rule should be viewed as a local approximation; the behavior of the fishery (firms, regulator, and fish stock) never come close to this unrealistic prediction at the boundary of the state space. 
Requiring that harvest be equal to the TAC implies $T A C_{t}=c+d X_{t}=Y_{t}=X_{t}\left(1-e^{-q E_{t} T_{t}}\right)$. Solving $c+d X_{t}=X_{t}\left(1-e^{-q E_{t} T_{t}}\right)$ for $T_{t}$ yields

$$
T_{t}=\left[\frac{1}{q E_{t}}\right] \ln \left[\frac{X_{t}}{\left[(1-d) X_{t}-c\right]}\right]=\left[\frac{-1}{q E_{t}}\right] \ln \left[\frac{\left[(1-d) X_{t}-c\right.}{X_{t}}\right]
$$

Using the fact that the TAC equals $Y_{t}=X_{t}\left(1-e^{-q E_{t} T_{t}}\right)$, and given the expression for $T_{t}$ in Equation (3), we might write the difference equations for $X_{t+1}-X_{t}$ and $E_{t+1}-E_{t}$ as follows.

$$
\begin{aligned}
& X_{t+1}-X_{t}=r X_{t}\left(1-X_{t} / K\right)-c-d X_{t} \\
& E_{t+1}-E_{t}=\eta\left[p\left(c+d X_{t}\right)-(v / q) \ln \left[X_{t} /\left[(1-d) X_{t}-c\right]\right]-f E_{t}\right]
\end{aligned}
$$

In iterative form, System (4) may be written as

$$
\begin{aligned}
& X_{t+1}=\left[1+r\left(1-X_{t} / K\right)-d\right] X_{t}-c \\
& E_{t+1}=(1-\eta f) E_{t}+\eta\left[p\left(c+d X_{t}\right)-(v / q) \ln \left[X_{t} /\left[(1-d) X_{t}-c\right]\right]\right]
\end{aligned}
$$

which is the regulated open access analogue to System (1).

Evaluating the first equation in steady state, where $X_{t+1}=X_{t}=X$, one can show that the steady-state stock is the positive root of a quadratic given by

$$
X_{R O A}=\frac{K(r-d)}{2 r}+\sqrt{\left[\frac{K(r-d)}{2 r}\right]^{2}-\frac{K c}{r}}
$$

From the second equation in System (5) one can show that the steady-state level of effort is

$$
E_{R O A}=(p / f)\left(c+d X_{R O A}\right)-(v /(f q)) \ln \left[\frac{X_{R O A}}{\left[(1-d) X_{R O A}-c\right]}\right]
$$

The stability of the regulated open access equilibrium will depend on the absolute value of the trace and the determinant of the Jacobian 


$$
J=\left[\begin{array}{cc}
1+r-d-2 r X_{R O A} / K & 0 \\
\eta p d-(v / q)\left\{\frac{\left[c(1-d) X_{R O A}-\left[(1-d) X_{R O A}\right]^{2}+1\right.}{X_{R O A}\left[(1-d) X_{R O A}-c\right]}\right\} & 1-\eta f
\end{array}\right]
$$

As was the case for pure open access, the necessary and sufficient condition for $\left[X_{R O A}, E_{R O A}\right]$ to be stable is $2>1+\operatorname{det}(J)>|\operatorname{Tr}(J)|$.

The fact that $a_{1,2}=0$ in the above Jacobian implies that $X_{t+1}$ evolves independently of $E_{t}$. The fixed point $X_{R O A}$, given by Equation (6), will be reached provided $\left|1+r-d-2 r X_{R O A} / K\right|<1$. The regulated open access equilibrium will be unstable if the necessary and sufficient condition based on the Jacobian is not satisfied. As in the model of pure open access, instability can arise as the adjustment parameter, $\eta$, increases. In Figure 2 we show three cases using the parameters for Area 3 in the Pacific halibut fishery as estimated by Homans and Wilen (1997). In Figure 2(a), $\left[X_{R O A}, E_{R O A}, T_{R O A}\right]$ is a stable node. In Figure 2(b), $\left[X_{R O A}, E_{R O A}, T_{R O A}\right]$ is stable but with damped oscillations in $E_{t+1}$ as $X_{t+1} \rightarrow X_{R O A}$. In Figure 2(c), $\left[X_{R O A}, E_{R O A}, T_{R O A}\right]$ is unstable with $E_{t+1}$ fluctuating between positive and negative values while $X_{R O A}=253.44$. This last case may not be viewed as economically realistic but is a mathematical possibility in the model of regulated open access. In the economically relevant equilibrium, the regulator maintains a healthy biological stock, but rents are still dissipated. Thus, the level of excess capital and economic waste can be even greater in the regulated open access case than in the pure open access case.

Figure 2. The Regulated Open Access System when $r=0.3119, K=416.87, q=0.000975$, $c=16.417, d=0.0575, f=2.0993, p=1.95$ (a) $\eta=0.3$, (b) $\eta=0.9$, and (c) $\eta=0.96$ when simulated from $\left[X_{0}, E_{0}\right]=[400,3]$. In (a)-(c), $\left[X_{R O A}, E_{R O A}, T_{R O A}\right]=[253.44,23.79,5.62]$. In (a), $\left[X_{R O A}, E_{R O A}, T_{R O A}\right]$ is a stable node. In (b), $\left[X_{R O A}, E_{R O A}, T_{R O A}\right]$ is stable with damped oscillations in $E_{t+1}$ as $X_{t+1} \rightarrow X_{R O A}$. In (c), [ $\left.X_{R O A}, E_{R O A}, T_{R O A}\right]$ is unstable with $E_{t+1}$ fluctuating between positive and negative values while $X_{R O A}=253.44$. 


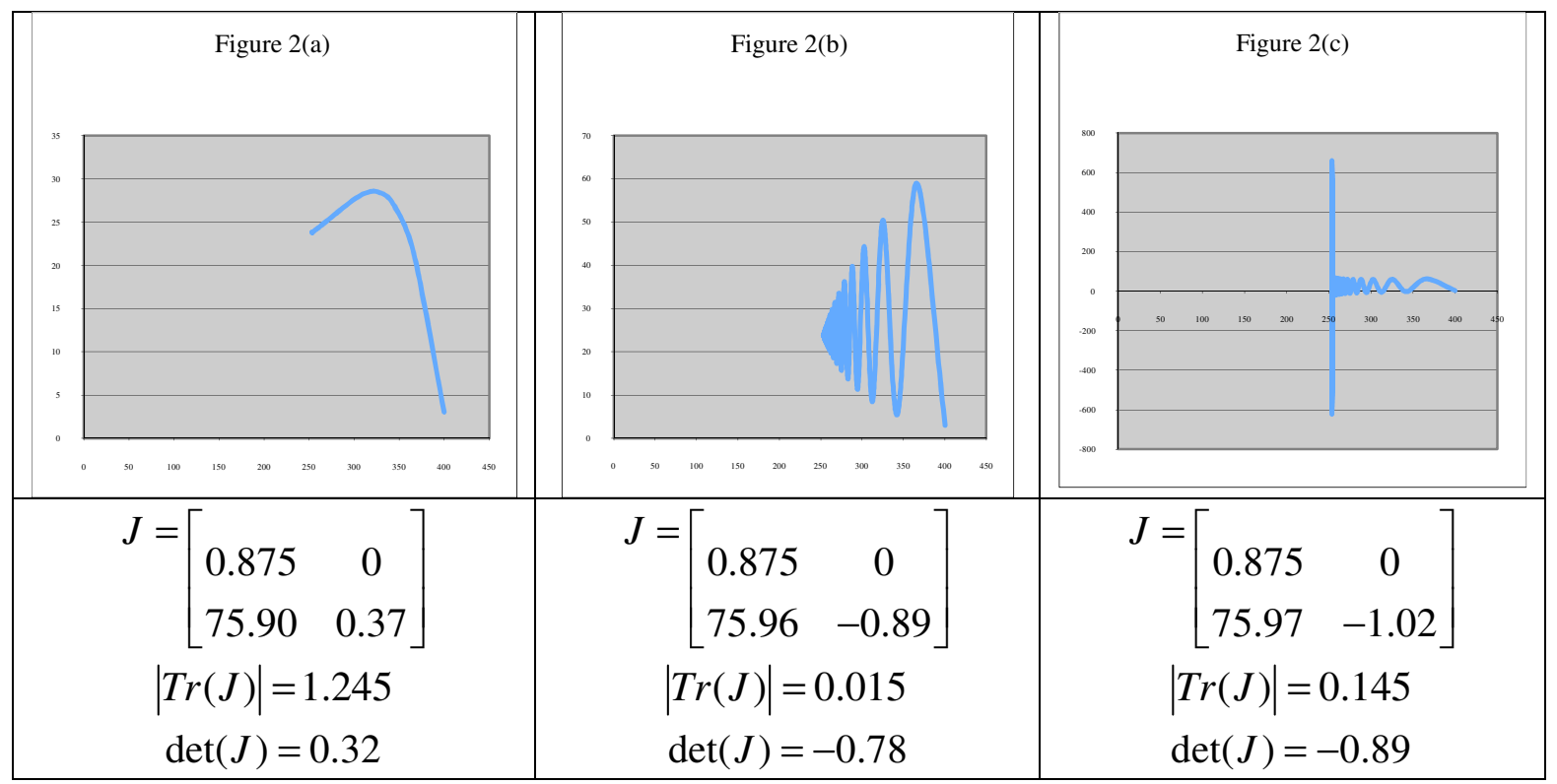

The Bioeconomic Optimum: Steady State and Approach Dynamics

If pure open access results in "too many vessels chasing too few fish," and regulated open access results in "a race for the fish," what's optimal and what mechanisms might be used to reach a bioeconomic optimum? We will present a simple model seeking to maximize discounted net revenue. The model yields analytic expressions for $X_{\infty}$, the stock level at the pure open access equilibrium, and $X^{*}$, the steady-state optimal biomass. We can then numerically solve for the optimal approach to $X^{*}$. We then briefly discuss the role that shadow prices play designing management policies.

The model is based on the following functional forms for net revenue and net growth: $\pi_{t}=p Y_{t}-(c / 2)\left(Y_{t}^{2} / X_{t}\right)$ and $F\left(X_{t}\right)=r X_{t}\left(1-X_{t} / K\right)$, where $Y_{t} \geq 0$ is the level of harvest measured in the same units as $X_{t}$. The problem seeking to maximize discounted net revenue subject to the dynamics of the harvested fish stock may be stated as

$$
\begin{array}{ll}
\underset{\left\{Y_{t}\right\}}{\operatorname{Maximize}} & \pi=\sum_{t=0}^{\infty} \rho^{t}\left[p Y_{t}-(c / 2)\left(Y_{t}^{2} / X_{t}\right)\right] \\
\text { Subject to } & X_{t+1}-X_{t}=r X_{t}\left(1-X_{t} / K\right)-Y_{t}, X_{0}>0 \text { given. }
\end{array}
$$

where $\rho=1 /(1+\delta)$ is the discount factor and $\delta>0$ is the per period discount rate.

The Lagrangian for this problem may be written as 


$$
L=\sum_{t=0}^{\infty} \rho^{t}\left\{p Y_{t}-(c / 2)\left(Y_{t}^{2} / X_{t}\right)+\rho \lambda_{t+1}\left[X_{t}+r X_{t}\left(1-X_{t} / K\right)-Y_{t}-X_{t+1}\right]\right\}
$$

where $\lambda_{t+1}$ is the shadow price on the fish stock in period $t+1$. This shadow price represents the marginal value of having a slightly larger fish stock in period $t+1$ (from the perspective of period $t+1$ ) presuming that the stock is being optimally managed.

The first-order conditions include the following three equations.

$$
\begin{aligned}
& p=c Y_{t} / X_{t}+\rho \lambda_{t+1} \\
& \lambda_{t}=(c / 2)\left(Y_{t} / X_{t}\right)^{2}+\rho \lambda_{t+1}\left[1+r\left(1-2 X_{t} / K\right)\right] \\
& X_{t+1}=X_{t}+r X_{t}\left(1-X_{t} / K\right)-Y_{t}
\end{aligned}
$$

Equations (10), (11), and (12) are obtained from $\partial L / \partial Y_{t}=0, \partial L / \partial X_{t}=0$, and $\partial L / \partial\left[\rho \lambda_{t+1}\right]=0$ , respectively. In steady state, where $X_{t+1}=X_{t}=X, Y_{t+1}=Y_{t}=Y$, and $\lambda_{t+1}=\lambda_{t}=\lambda$, Equations (10)-(12) imply

$$
r(1-2 X / K)+\frac{(c / 2)(Y / X)^{2}}{(p-c(Y / X))}=\delta
$$

$$
Y=r X(1-X / K)
$$

Equation (13) requires that the rate of return on the resource stock in steady state (the left-handside) equal the rate of discount, $\delta$, which in theory represents the rate of return on other investments elsewhere in the economy. It is the specific form of the more general equation $F^{\prime}(X)+\frac{\partial \pi(\bullet) / \partial X}{\partial \pi(\bullet) / \partial Y}=\delta$ as derived in Clark (1976). Equation (14) simply requires that harvest equal net growth, which must hold at any steady state (bioeconomic optimum, pure open access, or regulated open access). If one substitutes Equation (14) into Equation (13) and does some careful algebra, it can be shown that the optimal stock, $X^{*}$, is the positive root of a quadratic given by

$$
X^{*}=\frac{K(2 c r-2 p-\delta c)}{3 c r}+\sqrt{\left[\frac{K(2 c r-2 p-\delta c)}{3 c r}\right]^{2}+\frac{2 K^{2}(p-\delta p / r-c r / 2+\delta c)}{3 c r}}
$$


What is the equilibrium stock under pure open access? Without formulating the pure open access dynamical system for this specification, we can identify the steady-state pure open access stock from the following two equations: $\pi=p Y-(c / 2)\left(Y^{2} / X\right)=0$ and $Y=r X(1-X / K)$. The equation $\pi=0$ implies zero rent or "rent dissipation." Assuming $K>X_{\infty}>0$ these two equations imply

$$
X_{\infty}=K[1-2 p /(c r)]
$$

and $K>X_{\infty}>0$ if $1>2 p / c r>0$.

Because the Lagrangian is strictly concave in $Y_{t}$, the optimal approach to $X^{*}$ from an initial stock, $X_{0}>0$ will be asymptotic. As with our models of pure and regulated open access, we will provide a numerical example to illustrate.

Consider the model when $r=1, K=1, c=3, p=1$, and $\delta=0.05$. Suppose that initially the fish stock is at the pure open access equilibrium so that $X_{0}=X_{\infty}=0.3333$. From Equation (15) we calculate that $X^{*}=0.7345$. Note that $X^{*}>X_{M S Y}=K / 2>X_{\infty}$. We numerically approximate the optimal approach from $X_{\infty}$ to $X^{*}$ and show the time paths for $X_{t}^{*}$ and $Y_{t}^{*}$ in Figure 3.

Figure 3. The optimal asymptotic approach from $X_{0}=X_{\infty}=0.3333$ to $X^{*}=0.7345$.

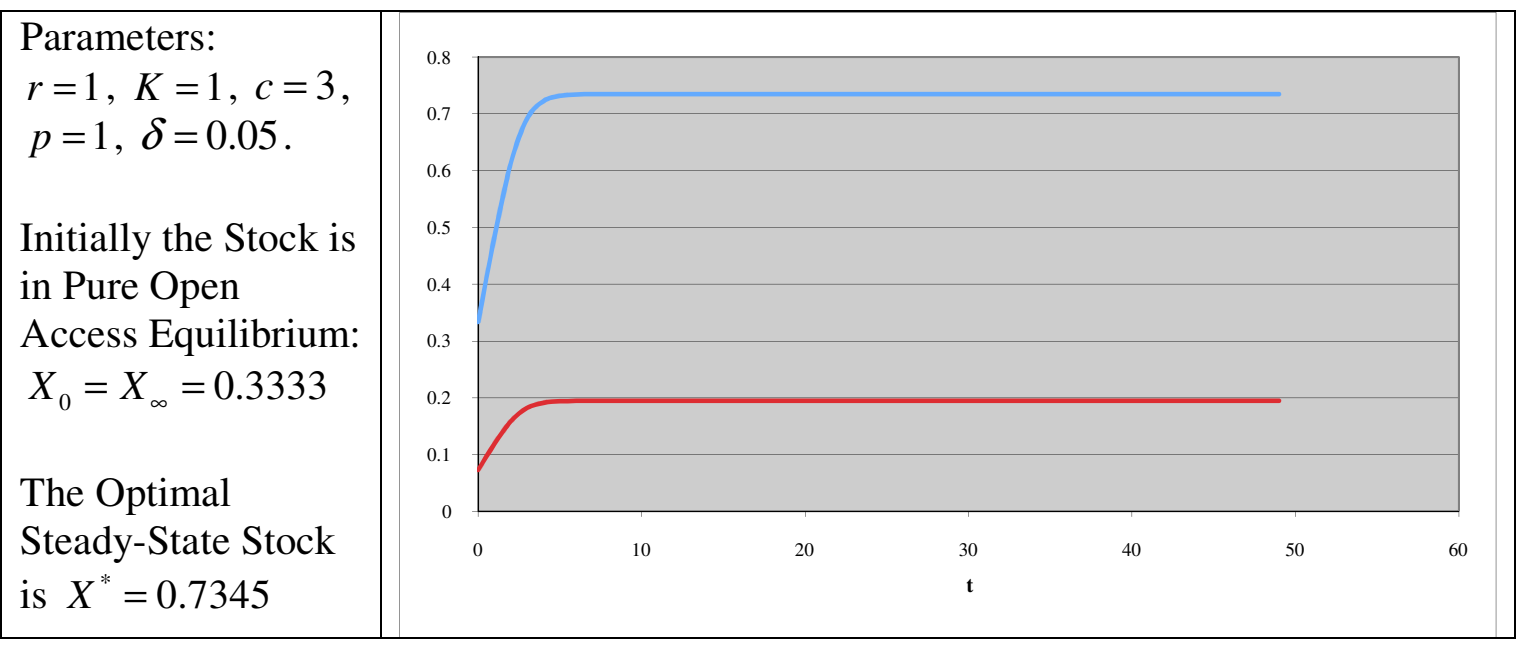

What is the key policy take-away from our problem seeking to maximize the present value of net revenues? The answer is the discounted shadow price, $\rho \lambda_{t+1}$. In Equation (10), the $\partial L / \partial Y_{t}=0$ required $p=c Y_{t} / X_{t}+\rho \lambda_{t+1}$. For optimality, the per-pound value of fish on the dock, $p>0$, 
must be equated to the marginal cost of harvest, $c\left(Y_{t} / X_{t}\right)$, plus the discounted shadow price, $\rho \lambda_{t+1}$. The discounted shadow price is often referred to as "user cost," and the sum referred to as "full marginal cost." It is the discounted shadow price that is typically not considered in the harvest decisions by individual fishers. By ignoring this important component of full marginal cost, too many fish are harvested and fish stocks become "economically overfished," with $X_{t}<X^{*}$.

What policies might induce fishers to account for $\rho \lambda_{t+1}$ in their harvest decisions. To an economist, the obvious answer is a "landings tax" per pound of fish brought to port. The intuition is the same as a Pigouvian fee (i.e. a pollution tax) but in a dynamic context. There is a cost to society that the private agent does not consider when making harvest (or pollution) decisions, known as an externality. An appropriately scaled tax forces the agent to internalize the externality. If fishery managers can impose a landings tax of $\tau_{t}=\rho \lambda_{t+1}$, fishers would, in theory, equate after tax price to marginal cost or $\left(p-\tau_{t}\right)=c\left(Y_{t} / X_{t}\right)$, thus satisfying Equation (10).

However, taxes are not popular with fishers who have collectively influenced fisheries management legislation in the U.S. Is there another way to introduce $\rho \lambda_{t+1}$ into the calculus of fishers? What if optimal harvest, $Y^{*}=r X^{*}\left(1-X^{*} / K\right)$, in the above model, were divided into $n$ small shares, $s=Y^{*} / n$. Suppose these shares were auctioned off to would-be fishers, along with the option that they could be resold (transferred) if the auction buyer decided not to fish a share during the season. The market clearing auction price, or the price in the market for "individual transferable quota," $P_{s, t}$, should, in theory, also equate to the discounted shadow price, $P_{s, t}=\rho \lambda_{t+1}$. The fact that the option to fish a share of total harvest can be resold introduces an opportunity cost to fishing. The fisher could, at the margin, earn $p-c\left(Y_{t} / X_{t}\right)$, if he or she decides to fish that share, or it could be sold for $P_{s, t}=\rho \lambda_{t+1}$. The market for transferable quota will be in equilibrium when $P_{s, t}=p-c\left(Y_{t} / X_{t}\right)$ which again establishes our required optimality condition in Equation (10).

\section{Optimal Escapement with Stochastic Growth}

Our last model in this section was developed by Reed (1979) to consider the role of uncertainty in renewable resource management. In it, the fish stock in period $t+1$ is stochastically determined by "escapement" in period $t$. By escapement, we mean the biomass that was not harvested in the previous period, $S_{t}=X_{t}-Y_{t}$. The fish stock in period $t+1$ is determined by the stochastic map, $X_{t+1}=z_{t+1} G\left(S_{t}\right)$ where the $z_{t+1}$ are independent, and identically distributed random variables with expected value $\mathrm{E}\{z\}=1$ and positive variance, $\sigma_{z}^{2}>0$. 
Suppose that the fishery production function takes the form as in the model of regulated open access but now

$$
Y_{t}=X_{t}\left(1-e^{-q E_{t}}\right)
$$

The cost of fishing in period $t$ is assumed to depend only on the level of effort as given by the cost equation $C_{t}=c E_{t}$, where $c>0$ is a variable cost coefficient. Solving the production function for effort yields

$$
E_{t}=(1 / q) \ln \left[X_{t} /\left(X_{t}-Y_{t}\right)\right]=(1 / q) \ln \left[X_{t} / S_{t}\right]=(1 / q)\left[\ln X_{t}-\ln S_{t}\right]
$$

where $\ln [\bullet]$ is the natural log operator. Substituting this last expression into the cost equation yields the cost function

$$
C_{t}=(c / q)\left[\ln X_{t}-\ln S_{t}\right]
$$

Net revenue in period $t$ is given by

$$
\pi_{t}=p Y_{t}-(c / q)\left[\ln X_{t}-\ln S_{t}\right]=p\left(X_{t}-S_{t}\right)-(c / q)\left[\ln X_{t}-\ln S_{t}\right]
$$

Now for a critical observation! If we define $N(m)=p m-(c / q) \ln (m)$, we can write net revenue as a separable function of $X_{t}$ and $S_{t}$.

$$
\pi_{t}=N\left(X_{t}\right)-N\left(S_{t}\right)
$$

The problem of maximizing the expected value of discounted net revenue subject to stochastic recruitment may be stated as

$$
\begin{array}{ll}
\underset{\left\{S_{t}\right\}}{\operatorname{Maximize}} & E_{0}\left\{\sum_{t=0}^{T} \rho^{t}\left[N\left(X_{t}\right)-N\left(S_{t}\right)\right]\right\} \\
\text { Subject to } & X_{t+1}=z_{t+1} G\left(S_{t}\right) \\
& X_{0} \text { given, } z_{t+1} \text { i.i.d.with } E\left\{z_{t+1}\right\}=1
\end{array}
$$

where $E_{0}\{\bullet\}$ and all subsequent $E_{T-t}\{\bullet\}$ will denote the expectation operator taken from the subscripted period. Momentarily we will let $T \rightarrow \infty$, but for now assume $T$ is finite. Our solution will employ dynamic programming and so we start in period $t=T$ where the value function may be written as 


$$
V_{T}=\operatorname{Max}\left[N\left(X_{T}\right)-N\left(S_{T}\right)\right]
$$

Maximization of the bracketed expression on the right-hand-side of Equation (22) with respect to $S_{T}$ requires $-N^{\prime}\left(S_{T}\right)=-\left(p-(c / q)\left(1 / S_{T}\right)=0\right.$ and implies $S_{T}^{*}=c /(p q)$ as the optimal escapement level in $t=T$. This escapement level is sometimes called the open access escapement level because it corresponds to $X_{\infty}=c /(p q)$ from our model of pure open access.

In period $t=T-1$ the value function is

$$
\begin{aligned}
V_{T-1} & =\operatorname{Max}_{S_{T-1}}\left[N\left(X_{T-1}\right)-N\left(S_{T-1}\right)+\rho E_{T-1}\left\{V_{T}\right\}\right] \\
& =\operatorname{Max}_{S_{T-1}}\left[\rho E_{T-1}\left\{N\left(z_{T} G\left(S_{T-1}\right)\right)\right\}-N\left(S_{T-1}\right)+N\left(X_{T-1}\right)-\rho N(c /(p q))\right]
\end{aligned}
$$

In going from the first line to the second line in Equation (23), we substitute $V_{T}=N\left(z_{T} G\left(S_{T-1}\right)\right)-N(c /(p q))$ inside the expectation operator. The last two terms in the second line of (23) are constants and the value of $S_{T-1}$ that maximizes the bracketed expression also maximizes

$$
W\left(S_{T-1}\right)=\rho E_{T-1}\left\{N\left(z_{T} G\left(S_{T-1}\right)\right)\right\}-N\left(S_{T-1}\right)
$$

If $W\left(S_{T-1}\right)$ is quasi-concave, the first-order condition is also sufficient. It requires

$$
W^{\prime}\left(S_{T-1}\right)=\rho E_{T-1}\left\{N^{\prime}\left(z_{T} G\left(S_{T-1}\right)\right) z_{T} G^{\prime}\left(S_{T-1}\right)\right\}-N^{\prime}\left(S_{T-1}\right)=0
$$

With $G^{\prime}\left(S_{T-1}\right)$ independent of $z_{T}$, Equation (25) implies

$$
G^{\prime}\left(S_{T-1}\right)\left[\frac{E_{T-1}\left\{z_{T} N^{\prime}\left(z_{T} G\left(S_{T-1}\right)\right)\right\}}{N^{\prime}\left(S_{T-1}\right)}\right]=(1+\delta)
$$

Equation (26) is one equation in one unknown and may be solved for $S_{T-1}^{*}$. Knowing $S_{T-1}^{*}$, we may write $V_{T-1}$ as

$$
V_{T-1}=N\left(X_{T-1}\right)-N\left(S_{T-1}^{*}\right)+\rho E_{T-1}\left\{N\left(z_{T} G\left(S_{T-1}^{*}\right)\right)\right\}-\rho N(c /(p q))
$$

In $t=T-2$ the value function becomes 


$$
\begin{aligned}
V_{T-2}= & \operatorname{Max}_{S_{T-2}}\left[N\left(X_{T-2}\right)-N\left(S_{T-2}\right)+\rho E_{T-2}\left\{V_{T-1}\right\}\right] \\
= & \operatorname{Sax}_{S_{T-2}}\left[\rho E_{T-2}\left\{N\left(z_{T-1} G\left(S_{T-2}\right)\right)\right\}\right. \\
& -N\left(S_{T-2}\right)+N\left(X_{T-2}\right)-\rho E_{T-2}\left\{N\left(S_{T-1}^{*}\right)\right\} \\
& \left.+\rho^{2} E_{T-2}\left\{N\left(z_{T} G\left(S_{T-1}^{*}\right)\right)\right\}-\rho^{2} N(c /(p q))\right]
\end{aligned}
$$

In the second line of Equation (28), $X_{T-2}, S_{T-1}^{*}$ and $S_{T}^{*}=c /(p q)$ are given [known constants or known from Equation (26)]. Thus, the last four terms in $V_{T-2}$ are constants. The optimal level of escapement, $S_{T-2}^{*}$, that maximizes the right-hand-side of Equation (28) also maximizes

$$
W\left(S_{T-2}\right)=\rho E_{T-2}\left\{N\left(z_{T-1} G\left(S_{T-2}\right)\right)\right\}-N\left(S_{T-2}\right)
$$

Compare Equations (29) and (24). While the period index is one period earlier in Equation (29), Equations (24) and (29) have the same form and if we continued to work our way back in time the same form would emerge for $W\left(S_{T-3}\right), W\left(S_{T-4}\right)$, and so on, back to $W\left(S_{0}\right)$.

Now let $T \rightarrow \infty$. In any period the optimal escapement policy, $S^{*}$, must maximize

$$
W(S)=\rho E_{z}\{N(z G(S))\}-N(S)
$$

Taking a derivative, and noting again that $G^{\prime}(S)$ is independent of $z, S^{*}$ must also satisfy

$$
G^{\prime}(S)\left[\frac{E_{z}\left\{z N^{\prime}(z G(S))\right\}}{N^{\prime}(S)}\right]=(1+\delta)
$$

When there is no uncertainty, i.e. the distribution of $z$ is degenerate, Equation 31 reduces to a special case of Clark's (1976) $F^{\prime}(X)+\frac{\partial \pi(\bullet) / \partial X}{\partial \pi(\bullet) / \partial Y}=\delta \quad$, (see our Equation 13). Numerically it is perhaps easier to do a computer search for the $S^{*}$ that maximizes (30) than the $S^{*}$ that satisfies (31), but they must be the same. Once we have found the optimal (stationary) level of escapement, the optimal (adaptive) harvest policy takes the form

$$
\begin{aligned}
& Y_{t}^{*}=\left(X_{t}-S^{*}\right) \text { if } X_{t}>S^{*} \\
& Y_{t}^{*}=0 \text { if } X_{t} \leq S^{*}
\end{aligned}
$$

Stock and harvest will be fluctuating over time. It is unlikely that one will be able to determine the closed-form stationary distributions for $X_{t}$ or $Y_{t}$, but one could simulate the optimal 
harvest policy over a long horizon (say, $\mathrm{T}=1000$ ) and calculate the mean, variance, or other statistics for their distributions after a suitable transition from $X_{0}$.

The above model, with an optimal constant escapement policy, has been used to manage salmon in the U.S. and Canadian Pacific Northwest. Consider the case where $X_{t+1}=z_{t+1} S_{t} e^{r\left(1-S_{t} / K\right)}$ with $r>0$ being the intrinsic growth rate and $K>0$ being the environmental carrying capacity. Let the $z_{t+1}$ be drawn for the discrete distribution

$$
\begin{aligned}
& \operatorname{Pr}\left(z_{t+1}=z_{1}=0.5\right)=0.25 \\
& \operatorname{Pr}\left(z_{t+1}=z_{2}=1.0\right)=0.50 \\
& \operatorname{Pr}\left(z_{t+1}=z_{3}=1.5\right)=0.25
\end{aligned}
$$

We are assuming that $E\left\{X_{t+1}\right\}=G\left(S_{t}\right)=S_{t} e^{r\left(1-S_{t} / K\right)}$ but that $X_{t+1}$ could be $50 \%$ less $\left(z_{1}=0.5\right)$ or $150 \%$ more $\left(z_{3}=1.5\right)$, each with probability 0.25 . Recall that $N(m)=p m-(c / q) \ln (m)$. Suppose $r=2, K=200,000, p=2, q=1, c=4,000$, and $\delta=0.05$. Then the value $S=S^{*}$ which maximizes $W(S)$, as given by Equation (30), and which satisfies Equation (31), is $S^{*}=71,534$. Optimal escapement and harvest are shown in Figure 4.

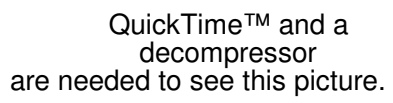

\section{Dynamic Spatial Models}


While economists have criticized fishery management for failing to understand and incorporate the basic insights of bioeconomics into objectives, more recently fishery management has come under fire for failing to incorporate modern fisheries ecology that emphasize spatial heterogeneity and spatial structure in population dynamics. When biological resources are viewed spatially, the use of a single non-spatial policy instrument to control harvest may fail to address an underlying spatial market failure.

A key insight that comes from extending dynamic models to spatial dynamics is that the productivity of a renewable resource system is endogenously determined by the spatial distribution of inputs. Consider a firm that owns two factories and has a fixed amount of an input $(E)$ to allocate across them such that $E_{1}+E_{2}=E$. Each factory has its own production technology given by $Y_{i}=f_{i}\left(E_{i}\right)$, and total output is then $Y=f_{1}\left(E_{1}\right)+f_{2}\left(E_{2}\right)$. Clearly, total production depends on the allocation of inputs across the two factories. If the production technologies are convex, i.e. the functions $Y_{i}=f_{i}\left(E_{i}\right)$ are concave, the solution to output maximization would be characterized by equimarginality: $f_{1}^{\prime}\left(E_{1}\right)=f_{2}^{\prime}\left(E_{2}\right)$. However, if there are non-covexities, the firm may produce more output by allocating all of its input to one factory or the other.

Interpreting these factories as different harvest locations in space reveals that one component of incorporating space into resource models is to reflect spatial heterogeneity in production. If different harvest locations represent different factories, one potential justification for forming a no-take marine reserve is if there are non-convexities in the biological production system. Such non-convexities could reflect biological depensation as a result of low reproductive success at low population densities or increasing fecundity returns to organism size, i.e. egg production is increasing at an increasing rate (Brown and Roughgarden 1997; Smith 2004). This interpretation is not spatial per se but just an application of production theory. As we will see in this section, moving from a model of spatial heterogeneity to one of spatial dynamics translates into moving from a description of how production is affected by changing input allocations to a description of how productivity itself is influenced by changing input allocations.

\section{Generalizing Pure Open Access}

The analogy of spatial heterogeneity reflecting $n$ production facilities with spatially explicit effort implies that we can write down a spatial system as a stacked model. If there is pure open access in each location and we assume logistic growth population dynamics, we would rewrite the system in (1) as

$$
X_{i, t+1}=\left[1+r_{i}-r_{i} X_{i, t} / K_{i}-q_{i} E_{i, t}\right] X_{i, t}, i=1,2, \ldots N
$$




$$
E_{i, t+1}=\left[1+\eta_{i}\left(p q_{i} X_{i, t}-c_{i}\right)\right] E_{i, t}, i=1,2, \ldots N
$$

Introducing spatial heterogeneity in the form of $n$ fishing locations means that there are $2 n$ state variables rather than just two; for each time period the model tracks the stock of fish in each location and the amount of effort in each location. The $i$ subscripts on parameters reflect various dimensions of spatial heterogeneity: fishing grounds have heterogeneous productivity $(r)$ or ability to support biomass $(K)$, it is easier to find fish (or fish aggregate more) in some places compared to others $(q)$, costs of effort are different in different fishing grounds due to different travel costs $(c)$, and speed of adjustment $(\eta)$ can vary over space, possibly reflecting differences in local economic conditions.

Managers might be interested in aggregate outcomes that add up effort, stock, and harvest over space. It turns out that this superficial introduction of space leads to aggregate dynamics that are qualitatively the same as the dynamics of the individual area. For example, if we have three areas identical to the fishery parameterized in Figures 1(a)-(c), the phase-plane diagrams appear the same, but are re-scaled. They are shown in Figures 5(a) - 5(c).

Figure 5(a)-(c). Spatial Pure Opens Access with No Dispersal

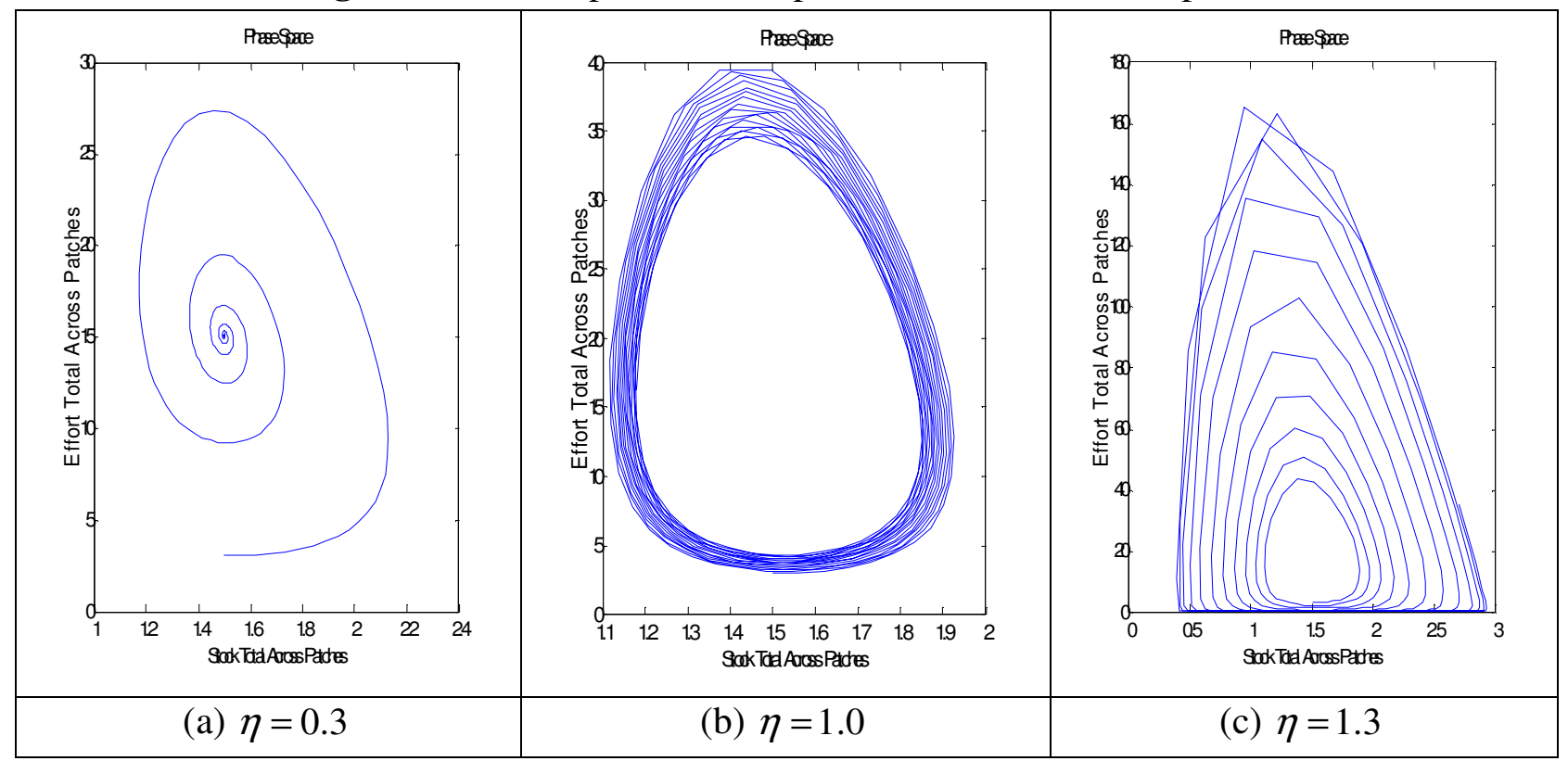

Considering the factory analogy, one might ask whether it makes sense to close one of these areas to fishing and fish only in the remaining open areas. Assuming logistic growth, there are no non-convexities because the system exhibits pure compensation (Clark 1990). The individual production sets are convex, so the aggregate production set is convex. Thus, without other assumptions and given no spatial heterogeneity in parameters, the system could not produce more harvest with the same amount of total effort redistributed over space. With spatial 
heterogeneity in parameters, one can produce more harvest by allocating a fixed quantity of effort over space heterogeneously. But if the systems in each location are stable, maximum harvest will occur where equimarginality holds. At this point, there are no spatial-dynamics because the fishing locations are connected only by virtue of the hypothetical existence of a fixed total amount of effort.

Spatial-dynamics alter the situation in a subtle way. Not only is production affected by changing input allocations, but changing input allocations alters productivity itself. In the factory example, whether it makes sense to shut down one of these factories and allocate the remaining input to the other factories depends on economies of scale. But the technology in one factory is not influenced by running the other factory. In the spatial dynamics of renewable resources, the activities in one area influence the productivity in the remaining areas (Smith, Sanchirico and Wilen 2009). In that sense, the production technology is endogenously determined by the level and spatial distribution of inputs.

Sanchirico and Wilen (1999) generalized the pure open access model to allow for both spatial heterogeneity and spatial connectivity. They follow the literature on metapopulation ecology that depicts a population as being composed of local subpopulations (called patches) in which growth, predation, and reproduction take place. These subpopulations are then connected via larval dispersal and/or adult migration. The Sanchirico and Wilen (1999) model nests the one in equation 1.1 by adding dispersal terms for both the harvest sector and the biological system.

$$
\begin{aligned}
& X_{i, t+1}=\left[1+r_{i}-r_{i} X_{i, t} / K_{i}-q_{i} E_{i, t}\right] X_{i, t}+\sum_{j=1}^{n} d_{i j} X_{j, t}, i=1,2, \ldots . n \\
& E_{i, t+1}=\left[1+\eta_{i}\left(p q_{i} X_{i, t}-c_{i}\right)\right] E_{i, t}+\sum_{\substack{j=1 \\
j \neq i}}^{n} \eta_{i j}\left[\left(p q_{i} X_{i, t}-c_{i}\right) E_{i, t}-\left(p q_{j} X_{j, t}-c_{j}\right) E_{j, t}\right], i=1,2, \ldots n
\end{aligned}
$$

The $d$ parameters regulate biological dispersal, i.e. the flow of biomass from one location to another. The biological model can be thought of as a discrete approximation to the Fisher reaction-diffusion system (Smith et al. 2009). In the effort equations, $\eta_{i}$ controls aggregate entry and exit for a patch analogous to the speed of adjustment in Vernon Smith's model (Smith 1969), whereas the $\eta_{i j}$ 's regulate the distribution of spatial effort across patches. Intuitively, when net rents are higher in patch $\mathrm{i}$ than in patch $\mathrm{j}$, fishing effort will flow toward patch $i$ from $j$. This system thus allows for spatial-dynamic linkages that originate in the biological system, in the economic system, or in both.

The introduction of dispersal ultimately changes the dynamics of the system. In the bioeconomic equilibrium of system 35, i.e. when $X_{i, t+1}=X_{i, t}$ and $E_{i, t+1}=E_{i, t}$ for all $i$, there will still be 
dispersal of the population across space, even though the stock and effort levels in each patch are constant (Sanchirico and Wilen 1999). The flux in the system occurs because each patch's population size is maintained by the balance between own patch net growth and harvesting and system-wide dispersal to and from the other patches. This feature reflects spatial-dynamic processes and does not arise when there is only spatial heterogeneity (Smith et al. 2009). Consider the same parameters above with a source-sink style dispersal. By source-sink we mean that some areas have net outflow of dispersal and others have net inflow regardless of the levels of the populations. For simplicity, we assume that $\eta_{i j}$ 's are all zero and that $\eta_{i}$ 's are the same across patches. These assumptions mean that patch-level entry and exit will serve to equilibrate rents over space and, ceteris paribus, the process will be slower. For $\eta=1.0$, patch 1 dynamics are now characterized by a stable focus, whereas patches 2 and 3(not pictured) remain stable limit cycles. Aggregating across the three areas thus leads to a stable limit cycle for aggregate effort and stock. These results are shown in Figures 6 (a) - (c).

Figure 6(a)-(c). Spatial Pure Open Access, Patch 1 is a Source, Patches 2 and 3 are Sinks.

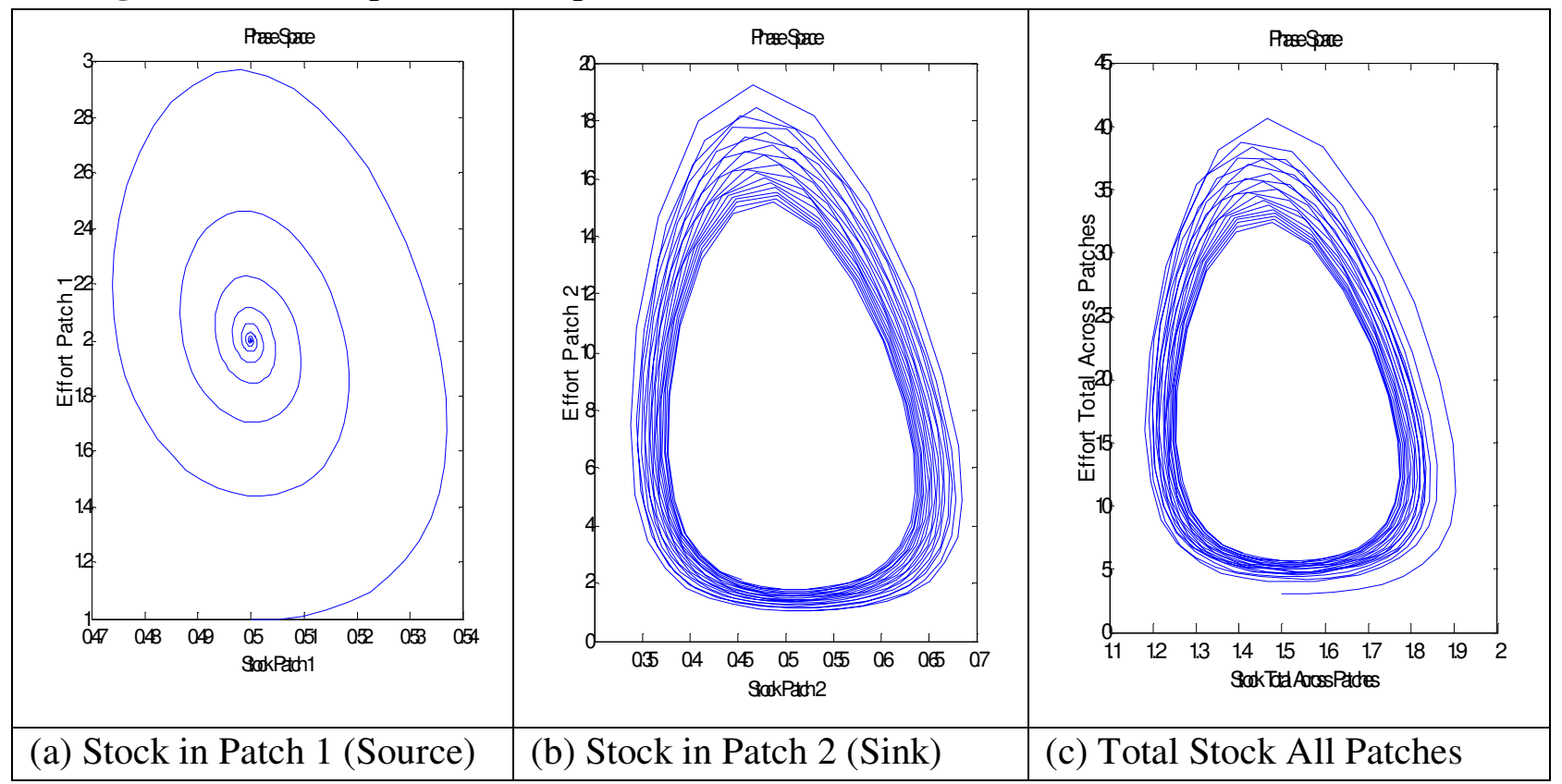

Not only do spatial-dynamics alter the dynamics of individual areas, they can change the overall payoffs. Even though we did not change any of the economic or biological productivity parameters and used the same initial conditions, the present value rent from the source-sink system is 9.0125 compared to 8.9811 for the system with no spatial dispersal (assuming a $7 \%$ discount rate). This immediately raises important questions. Are there gains from controlling the system spatially? Even in a system without non-convexities, is it possible that harvests would be greater if one of the areas were a no-take marine reserve? How closely does optimal management of spatial-dynamic systems parallel systems without any spatial features? 
One of the first papers to model the consequences of spatial management in a fishery was Polacheck (1990). Polacheck used a two-patch Beverton and Holt (1957) model with one patch representing the reserve and the other being the non-reserve. The model assumed that total fishing effort is unchanged by introducing a reserve, and the effort formerly in the reserve area redistributes uniformly in the non-reserve area, a typical assumption in the marine reserves modeling literature. Polacheck demonstrated that with high pre-reserve fishing effort, a reserve can increase the spawning stock biomass as a result of a shift in the age distribution of the population towards older organisms. Under some reserve scenarios, this also can increase the fishing yield per recruit. Like Polacheck, Holland and Brazee (1996) considered the case of fixed total fishing effort. They found that discounting is critical to determining whether a reserve can generate net benefits to fisheries. In some situations, a marine reserve could lead to higher present value rents, depending on how long it takes to recover populations and the discount rate itself. Pezzey et al. found that reserves can increase equilibrium catch if the pre-reserve biomass is less than half of the carrying capacity. In other words, reserves are more likely to generate positive net benefits if the fishery is heavily exploited before forming the reserve. Hannesson (1998) pointed out that reserves create the possibility of short-term rents, but ultimately reserves lead to rent dissipation if open access conditions are unaltered. Sanchirico and Wilen (SW) (2001) explored the effects of marine reserves using their n-patch spatial pure open access model.

Using the SW model and closing down the source patch, we alter the aggregate dynamics. In essence, the system transitions from one limit cycle to another. This result is important because the transition from one limit cycle to another makes a sharp but complicated empirical prediction about what will happen when a marine reserve is formed. Depending on the timing of the policy, the transition path involves non-monotonicities and different regions of the phase space that differ from simplistic predictions about marine reserve formation that tend to be monotonic.

Figure 7. A Marine Reserve in a Source-Sink System, $\eta_{i}=1.0$. 


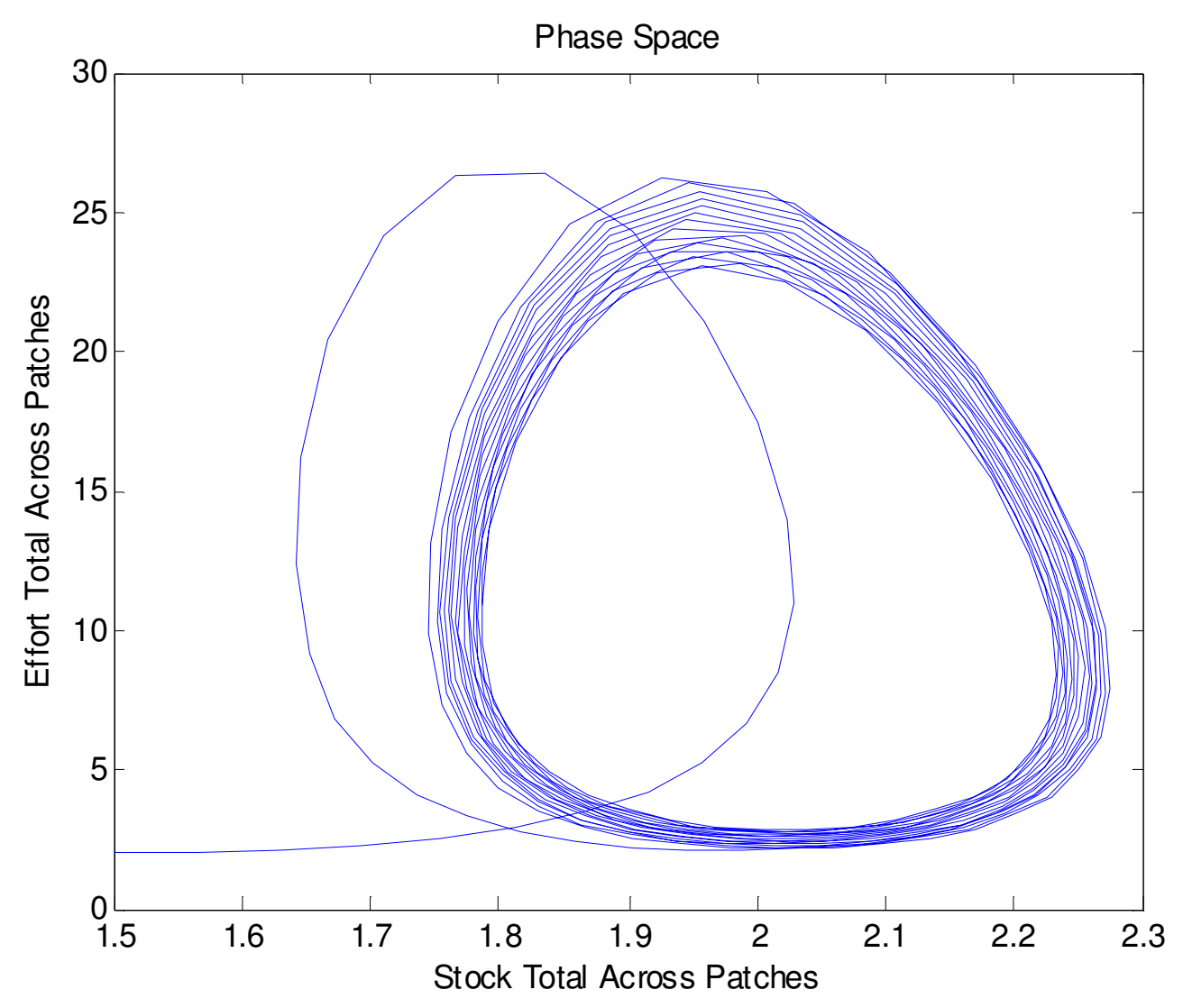

However, the present value of rents in this case is actually lower than in the pure open access case with no marine reserve, 8.7369 compared to $9.0125\left(\eta_{i}=1.0\right.$, shown in Figure 7$)$ or 18.7758 compared to $19.1132\left(\eta_{i}=0.3\right)$. One of the key findings in SW 2001 is that reserves are most likely to pay off in an otherwise open access system if the system is heavily overexploited. That allows the reserve to generate significant benefits through regenerating the reserve population and spillovers that compensate for the loss of fishing in the reserve with increased harvest in the remaining areas open to fishing. For instance, if we keep the same parameterization from above but start the initial stock at 0.1 in each patch rather than 0.5 , present value rents are -2.5593 with the marine reserve but -5.1164 with no reserve $\left(\eta_{i}=0.3\right.$, shown in Figure 8$)$ and -1.2493 with a reserve and -2.1683 with no reserve $\left(\eta_{i}=1.0\right)$. Note that negative rents occur in transition only to reflect potential sluggish adjustment; zero-rent is still imposed in equilibrium. Thus, it is possible that a marine reserve can improve or worsen economic outcomes if the remaining system is left in open access. This result generalizes to limited entry fisheries (Sanchirico and Wilen 2002)

Figure 8. A Marine Reserve in a Source-Sink System, $\eta_{i}=0.3$ (Combination of Stable Foci). 


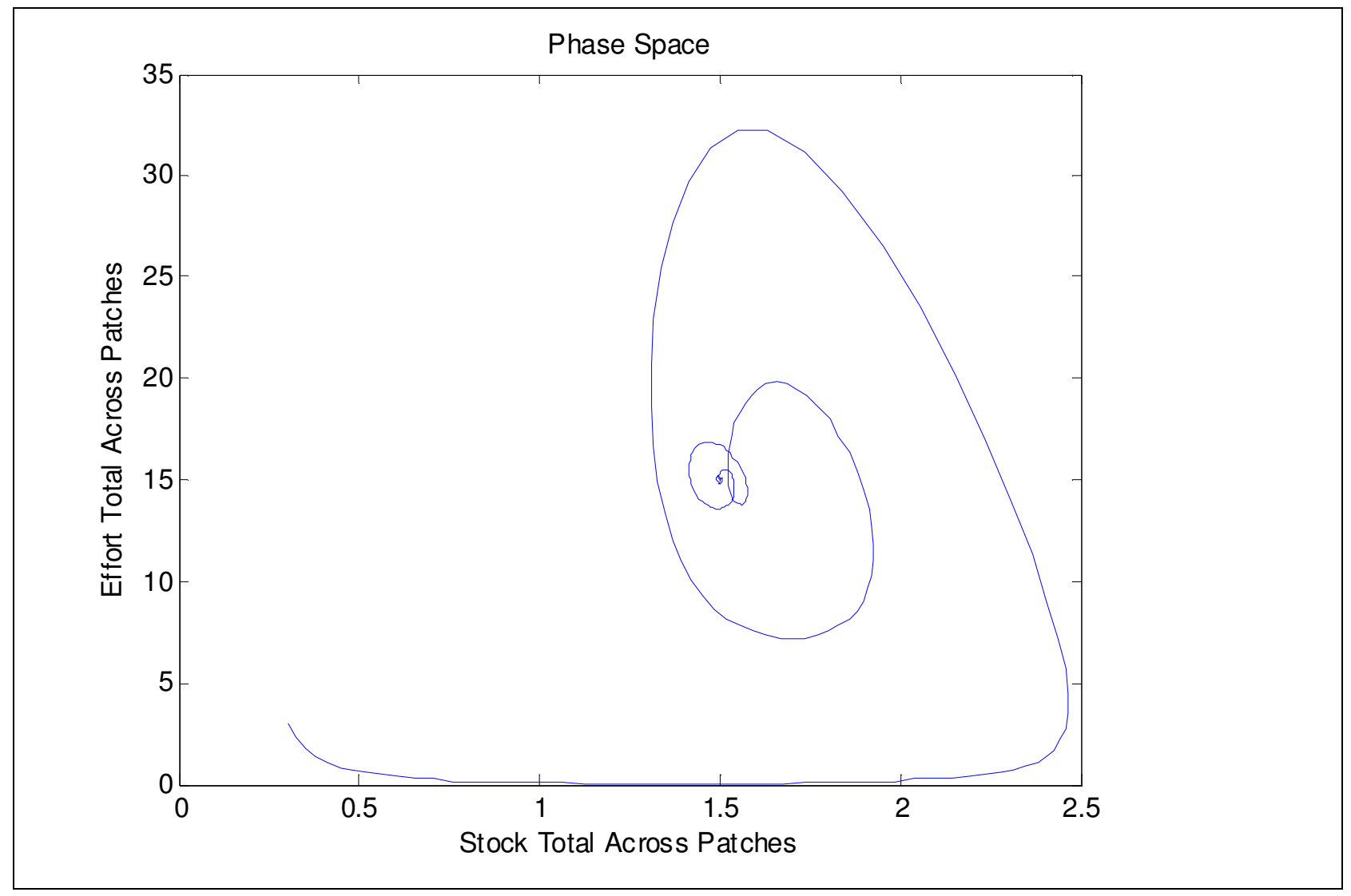

Optimal Management of Spatial-Dynamic Systems

Much of the literature on modeling spatial-dynamic fisheries focuses on whether a no-take marine reserve inserted into a fishery with its existing institutional setting would generate fishery benefits. A different question is whether a reserve is optimal and more generally how to optimize a spatial-dynamic system. Early work on this question focused on dividing a fishery into two areas and making explicit biological assumptions about the spatial-dynamic processes. Brown and Roughgarden (1997) analyzed a two-patch metapopulation characterized by biological returns and found that closing down one area can be optimal. Conrad (1999) divided a fishery into reserve and non-reserve areas with density-dependent dispersal connecting them and found that the present value of a reserve policy - in a deterministic model optimizing over the size of the reserve-is lower than the present value of optimal fishery management without a reserve. By introducing stochastic growth into the model, however, marine reserves can lower variability in fishable biomass. The deterministic model in Conrad did not include the non-convexity in the model presented by Brown and Roughgarden, which drove the latter's result of the optimality of a reserve. 
Sanchirico and Wilen (2005) formulated a model of optimal spatial-dynamic management of the n-patch SW (1999) system by introducing patch-specific effort taxes and patch-specific landings taxes. They allowed for different types of dispersal, including source-sink and densitydependence. They found that optimal taxes are delineated over space and time because the shadow value of biomass in the spatial-dynamic system is space- and time-specific. In a second best world of uniform taxes, a density-dependent system is implicitly controllable, but a sourcesink system is not. Thus, they found that under a second best system of uniform taxes, rents from a source-sink system deviate from the social optimum more than in other dispersal systems. In a parallel line of literature, Costello and Polasky (2008) built on the Reed (1979) model of stochastic control of renewable resource systems. They found that no-take reserves can be optimal at a particular point in time. The intuition follows directly from Reed's optimal escapement model. If the population in a patch is below the escapement threshold for that patch, then no harvest is optimal in the patch. In theory, a permanent no-take reserve can turn out to be optimal if the population in a location never rises above the escapement threshold, but such a conclusion cannot be drawn ex ante.

To provide further intuition about optimal spatial-dynamic management, consider a discrete-time and discrete-space version of the bioeconomic model presented above.

$$
\begin{aligned}
& \underset{\left\{Y_{i, t}\right\}}{\operatorname{Maximize}} \sum_{i=1}^{n} \sum_{t=0}^{\infty} \rho^{t}\left[p Y_{i, t}-(c / 2)\left(Y_{i, t}\right)^{2} / X_{i, t}\right] \\
& \text { Subject to } X_{i, t+1}-X_{i, t}=\left[r_{i}-r_{i} X_{i, t} / K_{i}\right] X_{i, t}+\sum_{j=1}^{n} d_{i j} X_{j, t}-Y_{i, t}, X_{i, 0}>0 \text { given }
\end{aligned}
$$

The associated Lagrangian for this problem is:

$$
L=\sum_{i=1}^{n} \sum_{t=0}^{\infty} \rho^{t}\left[p Y_{i, t}-(c / 2)\left(Y_{i, t}\right)^{2} / X_{i, t}+\rho \lambda_{i, t+1}\left\{X_{i, t}+\left[r_{i}-r_{i} X_{i, t} / K_{i}\right] X_{i, t}+\sum_{j=1}^{n} d_{i j} X_{j, t}-Y_{i, t}-X_{i, t+1}\right\}\right]
$$

Note that the shadow values $\lambda_{i, t+1}$ are location- and time-specific. This feature combined with the spatial dispersal terms $d_{i j}$ ensures that optimizing this system requires a fully integrated consideration of the spatial dynamics. To examine this model more closely, we will assume as above that there are three patches and three qualitatively distinct dispersal systems: independent, density dependent, and source-sink. In independent systems, $d_{i j}=0 \forall i, j$. With density dependence, biomass flows on the basis of density relative to a patch's carrying capacity. For 
simplicity, we assume that this process can be characterized with a single parameter $\theta$ such that the matrix of dispersal parameters $\mathbf{D}$ is: $\left[\begin{array}{ccc}-2 \theta / K_{1} & \theta / K_{2} & \theta / K_{3} \\ \theta / K_{1} & -2 \theta / K_{2} & \theta / K_{3} \\ \theta / K_{2} & \theta / K_{2} & -2 \theta / K_{3}\end{array}\right]$.

In the source-sink, we assume that the source is in patch 1 and patches 2 and 3 are sinks. The corresponding dispersal matrix $\mathbf{D}$ is: $\left[\begin{array}{ccc}-2 \theta & 0 & 0 \\ \theta & 0 & 0 \\ \theta & 0 & 0\end{array}\right]$. We further assume that $\theta$ is a fraction of the intrinsic growth rate in patch $1 r_{l}$. For the density-dependent and source-sink systems, we explore three scenarios: $\theta=0.05 r_{1}$ (low dispersal), $\theta=0.2 r_{1}$ (moderate dispersal), and $\theta=0.45 r_{1}$ (high dispersal). For all scenarios, we use the same parameters for patch-level biological and economic parameters from Figure 3.

Not surprisingly, with independent patches, we simply replicate the results in Figure 3. In a three-patch fishery with no dispersal, no heterogeneity across patches, and the same initial conditions, optimal management implies that we implement the same control policy in Figure 3 at each location and in each time period. Somewhat surprisingly, the same result holds for the density-dependent system; spatial management in this case means implementing the same control rule in each location. This result is consistent with the findings in Conrad (1999) for a deterministic spatial bioeconomic system. In that case, a reserve policy always led to lower present value rents because it violated equimarginality of an otherwise convex system. If we alter initial conditions, however, the optimal approach paths in the independent and density-dependent systems are not identical. Suppose initial conditions in the three areas are $X_{0,1}=0.3333 K_{1}, X_{0,2}=0.5 K_{2}$, and $X_{0,3}=0.3333 K_{3}$, and assume the moderate dispersal case. The density-dependent system has a more rapid approach to the optimal steady state. Figure 9 illustrates the two harvest paths for Patch 1.

Figure 9. Harvest Paths for Patch 1 in a Three-Patch Optimized Spatial Bioeconomic System under Density-Dependent Dispersal 


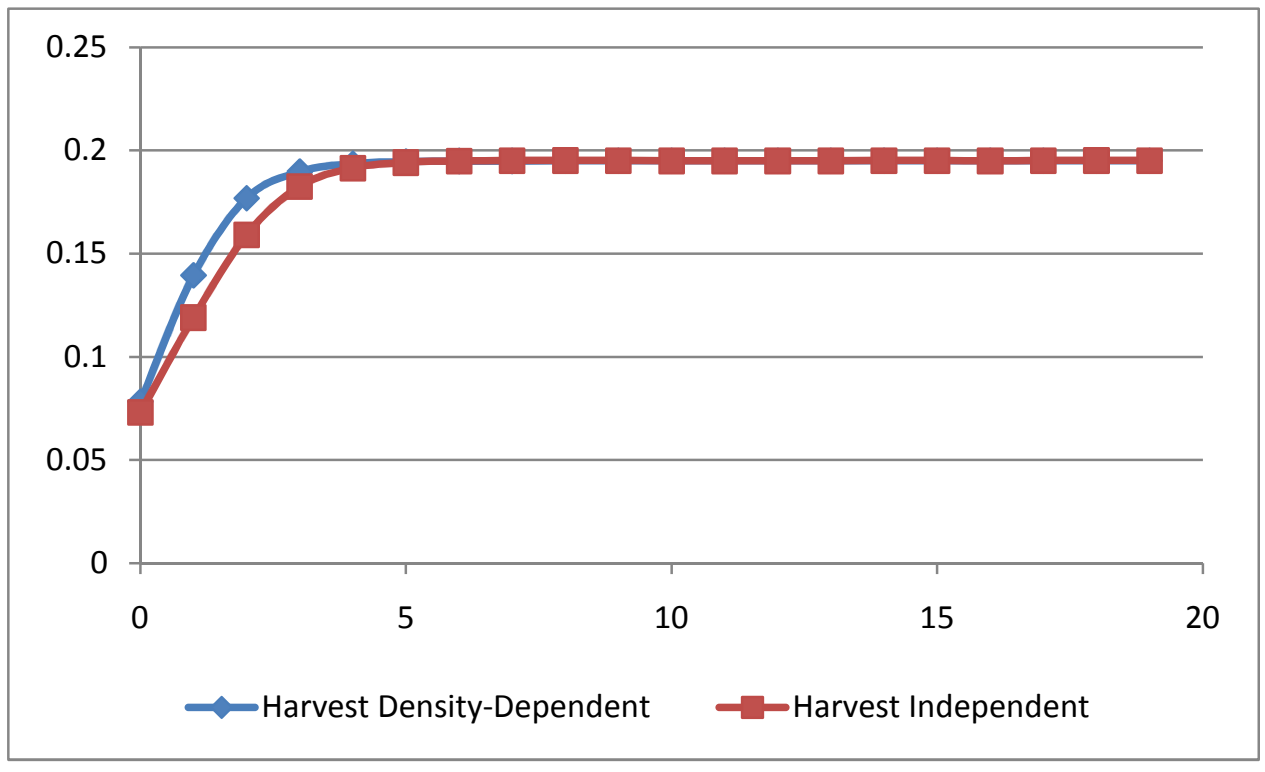

There are subtle differences between independent and density-dependent systems, and spatial heterogeneity can accentuate these differences. However, much of the discussion of spatial management centers around the case of source-sink systems in which it is possible to find that a marine reserve is the optimal policy.

Returning to the case of equal initial conditions, even with low dispersal, it is evident that spatially delineated management can increase rents. Figures 10 (a) - (b) depict the harvest ratio and stock ratio of Patch 1 (the source), which provides biomass to Patches 2 and 3 (the sinks). The ratio is the harvest (biomass) in Patch 1 to sum of the corresponding harvest (biomass) in the other patches. As a reference, the harvest and stock ratios would be 0.5 throughout for the independent case.

Figure 10(a)-(b). Harvest Ratio and Stock Ratio of Patch 1 to Patches 2 and 3 in the ThreePatch Optimized Spatial Bioeconomic System under Source-Sink Dispersal.

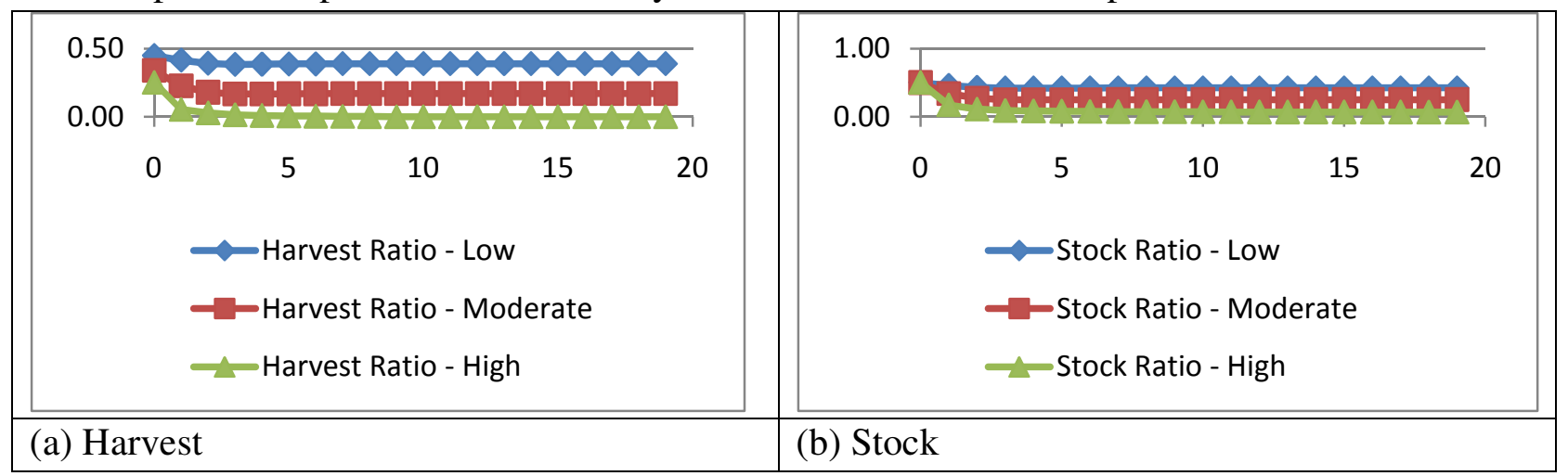

When dispersal is low, there is harvest in the source patch throughout transition phase and in steady state, and the level of harvest and stock are close to the levels in the sink patches. The 
presence of source-sink dynamics creates some incentive to tilt extraction slightly toward the sink patches. This tendency is more pronounced in the steady state than in the transition phase because the transition phase requires rebuilding populations in all locations to some extent, which is an artifact of initial conditions. Although there is less harvest in the steady state in patch 1 , the patch 1 steady-state stock is lower than that of patches 2 or 3 . The reason is simply that the dispersal process is exporting more of the biomass to the other areas than the compensating increase in biomass due to the lower level of harvest. This result also illustrates how the spatialdynamic system is in flux equilibrium; population levels stabilize in the steady state but there is net flow across spatial boundaries. The case of moderate dispersal is similar to that of low dispersal; equilibrium harvest and stock in the source patch are lower than those in a sink patch and the equilibrium is characterized by net flow of biomass across spatial boundaries. The difference is simply that the higher dispersal rate accentuates these effects.

With high dispersal, it is optimal to make the source patch a no-take marine reserve in the steady state. In transition, there is still some harvest in the source. The transition phase harvest occurs because all initial stocks are set to $0.3333 K_{i}$ such that the initial stock level in the source is much greater than its equilibrium stock level, whereas initial stocks in the other two patches are below their equilibrium levels. As a consequence, the harvest declines over time (until it reaches zero) in the source and rises over time (until it reaches a steady state) in each of the sink patches.

\section{Empirical Issues in Spatial Management}

The theoretical possibility that a marine reserve could lead to higher catches and even profits immediately raises empirical questions about the plausibility of a reserve benefiting a real fishery and whether existing reserves have increased catches. Smith and Wilen (2003, 2004) explored the potential for marine reserves to benefit the California sea urchin fishery by empirically modeling the behavior of the fishing fleet and coupling the results to an empirically grounded model of the urchin metapopulation. At first blush, urchin biology is particularly amenable to the use of marine reserves because reproduction is density-dependent, subpopulations are connected via larval dispersal, and egg production exhibits increasing returns to organism size (Smith 2004). Indeed, a bioeconomic model of the fishery in which effort is assumed to distribute uniformly across space shows substantial steady-state gains in harvest with marine reserves and in some scenarios can even find present value revenue increases (Smith and Wilen 2003). However, when economic behavior of the fleet is taken into consideration, these results reverse such that marine reserves lead to steady-state and transition phase losses to the fishery. Kaui and Alexander (2008) found similar results for the New Zealand abalone fishery. In contrast, Valderamma and Anderson found that rotating reserves can increase fishery profits for a different sessile species (sea scallops).

A key driver of the reversal in Smith and Wilen (2003) was the existence of de facto reserves in the actual fishery; some fishing grounds were sufficiently costly to access that they fed the 
remaining fishing grounds without imposing formal no-take reserves on the system. By not modeling these de facto reserves and the spatial heterogeneity of fishing opportunities, reserves end up seeming like a better policy than they would be. Though the modeling approach differed significantly, de facto reserves did not appear to be present in the spatial structure of the scallop fishery modeled by Valderamma and Anderson.

There has been considerably less work in the bioeconomics literature on whether reserves empirically have been beneficial or costly to fisheries. Most ex post studies of reserves have appeared in the biological literature and have focused on the effects of reserves within the reserve itself. Drawing on the emerging literature on program evaluation of environmental policy, Smith et al. (2006) conducted a retrospective analysis of marine reserves in the Gulf of Mexico reef fish fishery. They found that reserves initially decreased catches and that the catches continued to trend downward for 4.5 years after formation of the reserves. This result is consistent with empirically based modeling in Smith and Wilen (2004), who showed that economic adjustment following the formation of a reserve will lead to continued declines in catches for some period after the initial decline. Whether catches for Gulf of Mexico reef fish will turn back up as a result of biological spatial-dynamic processes has yet to be seen. In a companion paper, Smith et al. (2007) estimated a structural model of the population dynamics for gag grouper (just one species in the reef fish complex) and found evidence that the reserve stimulated biological productivity. Whether that productivity increase for the target species is enough to make up for fishery losses for other species is unclear and outside the scope of the model.

Are attempts at optimal spatial management of fisheries worth the effort? Sanchirico and Wilen (2005) concluded: "In an ideal world in which information is perfect and transactions costs are zero, it would be economically optimal to design management policies that account for spatial interconnections within and among patches by utilizing separate instruments for each spatial unit" (p. 46). Two recent papers examined some of the practical issues of spatial management when spatially-explicit stocks and processes are not known (Smith et al. 2009; Holland and Herrera 2011). In all of the spatial models discussed above, a key determinant of whether spatial management makes sense in general, and whether a no-take reserve is a good policy in particular, is the nature of spatial dispersal. The benefits of spatial management and the potential for a marine reserve to pay off for the fishery are greatest when researchers can find source-sink systems and identify which patches are sources and which are sinks.

Smith et al. 2009 explored conditions under which dispersal dynamics can be revealed from fishery-dependent data. If the spatial scale of fishing ground choice matches the spatial scale of metapopulation dynamics, it is possible to identify the bioeconomic parameters of the spatialdynamic system from fishery data alone as long as there is minimal observation error, i.e. error in the empirical relationship between catch and stock. When there is substantial observation 
error, resolution of the intrinsic growth and carrying capacity parameters erodes, but the economic parameters can still be resolved and surprisingly the ability to resolve the structure of the dispersal dynamics qualitatively is preserved. This finding suggests that there may be many opportunities to use existing data sets that are collected for purposes of fishery management to study dispersal dynamics. Holland and Herrera (2011) specifically questioned whether it is worth delineating management spatially when stock dynamics are characterized by uncertainty. They found that when the true structure is a spatial one, there are some circumstances when spatial delineation is beneficial. However, depending on parameters, it can be the case that incorrectly lumping together the whole fishery leads to higher profits and lower risks. With a binding system-wide total allowable catch (TAC), the risk of overexploiting a substock may be lower if regulators are unable to set substock TACs perfectly. This possibility added to the inevitably higher costs of monitoring and data collection questions the viability of spatial fisheries management.

\section{Conclusions}

This article has reviewed some of the important non-spatial models that were developed early in the evolution of bioeconomics as well as some of the spatial models developed since the late 1990s. The early models provided a theoretical framework for modeling pure open access (the tragedy of the commons), regulated open access (the race for the fish) and optimal resource management. The key concept emerging from the early models is the discounted shadow price of the resource in period $t+1$. The value of an additional fish on the dock must equal or exceed full marginal cost, which took the form $p=c Y_{t} / X_{t}+\rho \lambda_{t+1}$ in Equation (10). Attention to full marginal cost sparked interest in policy tools that solve the commons problem and align individual incentives of fishers with the social objectives of management. Many fisheries economists have argued that some version of an individual transferable quota (ITQ) aligns incentives in this way. Over the past several decades, there has been growing acceptance of ITQs for fisheries management and increased adoption.

The emergence of spatial models in bioeconomics followed a different intellectual history but nonetheless arrived at a similar emphasis on full marginal cost. Early spatial bioeconomics was motivated by the growth of theoretical and empirical work in metapopulation ecology that emphasized the importance of local spatially delineated processes of subpopulations and global interconnections among subpopulations. In some cases, metapopulation models were used to motivate policy interventions such as no-take marine reserves directly without any bioeconomic modeling. As economics entered the picture, a key interpretation of the metapopulation framework was that different areas might play a non-convex role in the growth (production) of commercially valuable renewable resources. Individual fishers left to their own devices would not necessarily align their effort in a way that harnesses these non-convexities to generate the highest value possible in the fishery. In other words, ignoring space in management would fail to account for full marginal cost. In this article, we reviewed some of the models that clarified 
these points, examined the role and net benefit of marine (no-take) reserves as a particular example, and pondered how to optimize a spatial-dynamic renewable resource system.

In the U.S., and to a large extent in other industrialized countries, we are simultaneously seeing a push toward the use of rights-based management like ITQs to solve the commons problem and a push toward ecosystem-based management. The use of spatial planning and spatial modeling is seen as one component of a broader conceptualization of ecosystem-based management that would also acknowledge multi-species interactions, the importance of habitat, competing uses of renewable resources, and the role of human-ecosystem interactions. As rights-based management and ecosystem-based management progress in parallel within policy circles, how will they ultimately be reconciled? Bioeconomic modeling is perfectly situated to contribute to this policy discussion. The acknowledgement of full marginal cost that comes out of bioeconomic modeling provides a unified framework for evaluating tradeoffs and designing policies across time (as in traditional bioeconomic models), species, use (or non-use) values, space, or some combination thereof.

There are also some specific open questions that spatial bioeconomics might address in the near future. First, when would temporary, rotational, no-take, areas increase the value of a fishery? Valderrama and Anderson (2007) show that such a rotational policy can increase the net value of relatively immobile species, like the Atlantic sea scallop. Could such policies also increase the value of landings in other fisheries, such as groundfish. If fixed costs (another non-convexity) give rise to pulse fishing, can a large fishing area be geographically partitioned into open and closed areas so that harvest and net value are increased annually. Biological non-convexities can also arise in such fisheries if older females are more fecund. By allowing a closed area to support older, more fecund, fish before it is opened to fishing, one might see greater annual biomass and net value even when some other areas are closed to fishing in a given year. Will economic pressures to dissipate rents in the remaining open areas undo these gains? Can spatial policies be sufficiently delineated to overcome these pressures?

Second, what role would permanent or temporary reserves play when the size of stochastic environmental shocks vary geographically? One of the benefits of spatial management, if local shocks are not highly correlated, would be to have a "spatial portfolio" that lowers the overall variance in yield and net value over a larger geographical area. Salmon runs in British Columbia and Alaska might benefit from a spatial portfolio approach to management. An insurance pool, funded by a tax on net revenues from fishers harvesting salmon runs where stock size exceeds escapement, might provide relief to fishers whose local runs are closed because stock size is less than or equal to the optimal escapement for those runs.

Third, what are the best locations for aquaculture facilities so as to minimize environmental damage, conflicts with other uses such as fisheries, and the potential for genetic "contamination" 
of wild stocks? Aquaculture now constitutes more than half of global seafood production for human consumption, and its potential interaction with fisheries in the marketplace is undeniable. As of this writing, the U.S. Department of Commerce is currently taking publicly comment on its draft aquaculture policy that includes language highlighting environmental challenges. As aquaculture policies move forward, spatial bioeconomic analysis might be fruitful for determining, for example, where to locate salmon aquaculture operations.

Although the focus of spatial bioeconomics has largely been at the level of a fishery, the lessons learned paint a general equilibrium story that hints at lessons for broader scales. What happens in one place affects what is and/or what should happen in another place in the same way that changes in one market can reverberate through the economy by affecting markets for inputs, substitutes, and complements. Spatial linkages can reflect physical connections dictated by the biological system, economic connections, or both, and ignoring these linkages can lead to an incomplete accounting of full marginal cost. In a similar sense, focusing on just one fishery at a time in modeling or in policy may lead to some unintended consequences. For instance, moving from a regulated open access fishery to an optimized one is likely to affect the availability of fishing capital for other fisheries that are not optimized. The vast majority of bioeconomic modeling is done in a partial equilibrium framework in which prices and costs are unaffected by what is happening in other fisheries. In this current policy climate in which fisheries management appears to be changing rapidly, there may be a role for general equilibrium bioeconomic modeling that is motivated by a spatial perspective.

\section{References}

Barrett, J. H., A. M. Locker, and C. M. Roberts. "The Origins of Intensive Marine Fishing in Medieval Europe: The English Evidence." Proceeding of the Royal Society 271(2004): 2417-2421.

Beverton, R. J. H., and H. S.J. On the Dynamics of Exploited Fish Populations. London: Chapman and Hall, 1957.

Bjorndal, T., and J.M. Conrad. "The Dynamics of an Open Access Fishery." Canadian Journal of Economics 20 (1987):74-85.

Brown, G. M., and J. Roughgarden. "A metapopulation model with private property and a common pool." Ecological Economics 22(N1)(1997): 65-71.

Clark, C. W. "Economics of Overexploitation." Science 181, no. 4100(1973): 630-634.

Clark, C. W. Mathematical bioeconomics: The optimal management of renewable resources. Vol. Chichester. 1st, 2nd, and 3rd editions, Pure and Applied Mathematics Series. New York, 1976,1990,2010. 
Conrad, J. M. "The Bioeconomics of Marine Sanctuaries." Journal of Bioeconomics 1(1999): 205-217.

Costello, C., and S. Polasky. "Optimal Harvesting of Stochastic Spatial Resources." Journal of Environmental Economics and Management 56, no. 1-18(2008).

Crutchfield, J. A., and A. Zellner. Economic Aspects of the Pacific Halibut Fishery. Vol. Volume 1, Number 1. Fishery Industrial Research. Washington, D.C.: U.S. Department of Interior, 1962.

Edelstein-Keshet, L. Mathematical Models in Biology. New York.: Random House, 1988.

Fisher, R. A. "The wave of advance of advantageous genes " Annals of Eugenics 7(1937): 355369.

Gordon, H. S. "Economic theory of a common property resource: the fishery." Journal of Political Economy 75(1954): 124-142.

Hannesson, R. "Marine Reserves: What will they accomplish?" Marine Resource Economics 13(1998): 159-170.

Hardin, G. "The Tragedy of the Commons." Science 162(1968): 1243-1247.

Holland, D. S., and R. J. Brazee. "Marine Reserves for Fisheries Management." Marine Resource Economics 11(1996): 157-171.

Holland, D. S., and G. E. Herrera. "Benefits and Risks of Increased Spatial Resolution in the Management of Fishery Metapopulations Under Uncertainty." Natural Resource Modeling 23, no. 4(2011): 494-520.

Homans, F. R., and J. E. Wilen. "A model of regulated open access resource use." Journal of Environmental Economics and Management 32, no. 1(1997): 1-21.

Jevons, W. S. The Coal Question; An Inquiry Concerning the Progress of the Nation and the Probable Exhaustion of Our Coal Mines. London: Macmillan and Company, 1865.

Jury, E. I. 1971. "The Inners Approach to Some Problems in System Theory," IEEE Trans. Automatic Contr., AC-16, 233-240.

Kahui, V., and W. R. J. Alexander. "A bioeconomic analysis of marine reserves for paua (abalone) management at Stewart Island, New Zealand." Environmental \& Resource Economics 40, no. 3(2008): 339-367.

Kain, R. J. P., J. Chapman, and R. R. Oliver. The Enclosure Maps of England and Wales 15951918. Cambridge, United Kingdom: Cambridge University Press, 2004. 
May, R.M. "Simple mathematical models with very complicated dynamics." Nature 261 (1976): 459-467.

Pezzey, J. C. V., C. M. Roberts, and B. T. Urdal. "A simple bioeconomic model of a marine reserve." Ecological Economics 33(2000): 77-91.

Polacheck, T. "Year Round Closed Area as a Management Tool." Natural Resource Modeling 4(1990): 327-354.

Reed, W. J. "Optimal Escapement Levels in Stochastic and Deterministic Harvesting Models." Journal of Environmental Economics and Management 6(1979): 350-363.

Sanchirico, J. N., and J. E. Wilen. "A Bioeconomic Model of Marine Reserve Creation." Journal of Environmental Economics and Management 42(2001): 257-276.

Sanchirico, J. N., and J. E. Wilen. "Bioeconomics of Spatial Exploitation in a Patchy Environment." Journal of Environmental Economics and Management 37(1999): 129150.

Sanchirico, J. N., and J. E. Wilen. "The impacts of Marine Reserves on Limited-Entry Fisheries." Natural Resource Modeling 15, no. 3(2002): 380-400.

Sanchirico, J. N., and J. E. Wilen. "Optimal Spatial Management of Renewable Resources: Matching Policy Scope to Ecosystem Scale." Journal of Environmental Economics and Management 50(2005): 23-46.

Schaefer, M. B. 1957. "Some Considerations of Population Dynamics and Economics in Relation to the Management of Marine Fisheries," Journal of the Fisheries Research Board of Canada, 14:669-681.

Scott, A. "The Fishery: The Objectives of Sole Ownership.” Journal of Political Economy 63 (1955): 116-124.

Smith, M. D. "Fishing Yield, Curvature, and Spatial Behavior: Implications for Modeling Marine Reserves." Natural Resource Modeling 17, no. 3(2004): 273-298.

Smith, M.D. "Bioeconometrics: Empirical Modeling of Bioeconomic Systems." Marine Resource Economics 23(2008):1-23.

Smith, M.D. and J.E. Wilen. "The Marine Environment: Fencing the Last Frontier.” Review of Agricultural Economics 24, no. 1 (2002): 31-42.

Smith, M. D., J. N. Sanchirico, and J. E. Wilen. "The economics of spatial-dynamic processes: Applications to renewable resources." Journal of Environmental Economics and Management 57, no. 1(2009): 104-121. 
Smith, M. D., and J. E. Wilen. "Economic impacts of marine reserves: the importance of spatial behavior." Journal of Environmental Economics and Management 46, no. 2(2003): 183206.

Smith, M. D., and J. E. Wilen. "Marine Reserves with Endogenous Ports: Empirical Bioeconomics of the California Sea Urchin Fishery." Marine Resource Econ. 19(2004): 85-112.

Smith, M. D., J. J. Zhang, and F. C. Coleman. "Effectiveness of marine reserves for large-scale fisheries management." Canadian Journal of Fisheries and Aquatic Sciences 63, no. 1(2006): 153-164.

Smith, M. D., J. J. Zhang, and F. C. Coleman. "Structural modeling of marine reserves with Bayesian estimation." Marine Resource Economics 22, no. 2(2007): 121-136.

Smith, V. L. "Economics of Production from Natural Resources." American Economic Review 58, no. 3(1968): 409-431.

Smith, V. L. "On Models of Commercial Fishing." Journal of Political Economy 77(1969): 181198.

Valderrama, D., and J. L. Anderson. "Improving Utilization of the Atlantic Sea Scallop Resource: An Analysis of Rotational Management of Fishing Grounds." Land Economics 83(2007): 86-103.

Wilen, J.E. "Common Property Resources and the Dynamics of Overexploitation: The Case of the North Pacific Fur Seal." University of British Columbia, Resources Paper No. 3, September 1976. 